\title{
Tropical deep convection and density current signature in surface pressure: comparison between WRF model simulations and infrasound measurements
}

\author{
L. Costantino and P. Heinrich \\ CEA, DAM, DIF, 91297 Arpajon, France \\ Correspondence to: L. Costantino (lore.costantino@gmail.com)
}

Received: 13 March 2013 - Published in Atmos. Chem. Phys. Discuss.: 14 June 2013

Revised: 19 December 2013 - Accepted: 7 February 2014 - Published: 28 March 2014

\begin{abstract}
Deep convection is a major atmospheric transport process in the tropics, affecting the global weather and the climate system. In the framework of the ARISE (Atmospheric dynamics Research InfraStructure in Europe) project, we combine model simulations of tropical deep convection with in situ ground measurements from an IMS (International Monitoring System) infrasound station in the Ivory Coast to analyze the effects of density current propagation. The WRF (Weather Research and Forecasting) model is firstly run in a simplified (referred to as "idealized case") and highly resolved configuration to explicitly account for convective dynamics. Then, a coarser three-dimensional simulation (referred to as "real") is nudged towards meteorological reanalysis data in order to compare the real case with the idealized model and in situ observations.

In the 2-D run, the evolution of a deep convective cloud generates a density current that moves outward up to $30 \mathrm{~km}$ away from storm center. The increase in surface density (up to $18 \mathrm{~g} \mathrm{~m}^{-3}$ larger than surrounding air) is mostly due to the sudden temperature decrease (down to $-2{ }^{\circ} \mathrm{C}$, with respect to the domain-averaged value) from diabatic cooling by rain evaporation near ground level. It is accompanied by a dramatic decrease in relative humidity (down to $-50 \%$ ), buoyancy (down to $-0.08 \mathrm{~m} \mathrm{~s}^{-2}$ ), equivalent potential temperature $\left(25^{\circ} \mathrm{C}\right.$ lower than the planetary boundary layer (PBL)) and the rapid enhancement of horizontal wind speed (up to $15 \mathrm{~m} \mathrm{~s}^{-2}$ ). If temperature and density changes are strong enough, surface pressure becomes largely affected and highfrequency disturbances (up to several tens of $\mathrm{Pa}$ ) can be detected at the leading edges of density current. The moister and warmer air of subcloud layer is lifted up and replaced by
\end{abstract}

a more stable flow. The resulting thermodynamical instabilities are shown to play a key role in triggering new convection. If the initial environment is sufficiently unstable, they can give rise to continuous updrafts that may lead to the transition from single-cell to multicell cloud systems, even without the presence of an initial wind shear.

The overall consistence and similarity between idealized and real simulation, and the good agreement of the real case with in situ retrievals of temperature, pressure, wind speed and direction, seem to confirm the ability of 2-D and 3$\mathrm{D}$ models to well reproduce convective dynamics. Surface pressure disturbances, simulated in both the idealized and real cases as a consequence of cold pool propagation, are very similar to those recorded in the Ivory Coast. Present results stress the direct link between mesoscale convective system activity and high-frequency surface pressure variations, suggesting the possibility of developing a new method for real-time rainstorm tracking based on the ground-based infrasound monitoring of pressure field.

\section{Introduction}

The tropics are a region of Earth accounting for about two-thirds of global precipitation, most of which occurs in mesoscale cloud systems (Nesbitt et al., 2006), where large-scale deep convection represents the dominant transport process of heat, moisture and momentum in the free troposphere. Through planetary-wave activity (Hoskins and Karoly, 1981), large-scale tropical convective heating affects extra-tropical weather and energy cycle, ocean-atmosphere 
interaction and monsoon system variability. Understanding how deep convection forms and the different ways in which it organizes into multiscale cloud systems (in the $1-100 \mathrm{~km}$ range) is a fundamental issue to increase further our ability to model the climate system.

It is well established that several factors can act to affect the development of deep convection. Among these factors, sea surface temperature, dry-air entrainment and wind shear have usually been considered of primary importance (e.g., Bony et al., 1997; LeMone et al., 1998; Yoneyama and Parsons, 1999). In more recent times, scientists have focused on lesser known feedbacks (initialized by deep convection itself) that may have a critical role in the development of new convective cells. In particular, deep convective clouds can generate strong downdrafts that introduce cold and dry air into the planetary boundary layer (PBL). According to Betts (1976), this is probably due to the combined effect of evaporative cooling from rain and the downward transport of drier and potentially warmer air from above into the unsaturated subcloud layer. While evaporation (which is a heat sink and a water vapor source) cools and moistens, downward transport warms and dries the air. Therefore any combination of these effects can result. Analyzing data from northcentral Venezuela, Betts (1976) observed that the subcloud layer becomes typically colder and dryer after the occurrence of a tropical convective rain event. As the downdraft hits the ground and spreads outward, it may give rise to a consistent surface outflow (generally called "density current" or "cold pool") that replaces the warmer and moister air of the subcloud layer (lifted upward). The PBL is stabilized in the center of the spreading cold pool, but new convection is triggered at its boundaries (Tompkins et al., 2001). In the case of wind shear, the cloud may tilt and the less buoyant downdraft would not be weakened by the convective updraft. In this case, continuous updrafts may rise along the cold pool's leading edge, and if organized in a line, multicell storms may propagate downshear in the form of a squall line. The importance of cold pools in triggering new convection (organizing atmospheric circulation and supporting the development of deep convective clouds) has been stressed by the work of Khairoutdinov and Randall (2006), performed during the Large-scale Biosphere-Atmosphere (LBA) experiment in Amazonia. Performing several 3-D high-resolution simulations of convective system diurnal life cycle (using the forcing derived from the observation made during the field experiment), they showed that, if rain evaporation is (externally) suppressed, shallow convection does not transit to deep convection. In their analysis, cold pool dynamics is shown to play a key role in determining the formation of deep clouds, while other factors (e.g., boundary layer turbulence, additional tropospheric moistening, wind shear) are of secondary importance. Deep clouds, less subjected to buoyancy loss by dry-air entrainment than shallow clouds, penetrate the atmosphere more efficiently and develop stronger precipitation, which further increases cold pool intensity.
Since the early 1940s, it has been also observed that mesoscale cloud systems (MCS) are accompanied by different types of surface pressure perturbations (Orlanski, 1975), probably shaped by the system's precipitation and wind field (Knievel and Johnson, 1998). The idea that saturated downdrafts in thunderstorms can raise pressure hydrostatically, as a consequence of the atmospheric response to cooling by rain evaporation (e.g., Byers and Braham, 1949; Sawyer, 1946; Fujita, 1959) and water mass from hydrometeor loading (Sanders and Emanuel, 1977; Nicholls et al., 1988), is not new. Subsequent studies have also pointed out the role of minor nonhydrostatic effects leading to pressure enhancements, directly beneath the downdraft as a result of its impinging on the ground (Fujita, 1959, 1963) and at the leading edge of the outflow, with the rise of dynamic pressure as a consequence of the collision with the warmer inflow (Wakimoto, 1982). However, to our knowledge, there is a lack in the recent literature of the systematic study of statistical properties of the smaller and highest frequency surface pressure perturbations that modern numerical model simulations and state of the art instrument observations can easily and fruitfully address.

Some studies (e.g., Brunk, 1953) have also suggested that surface pressure perturbations are due to gravity waves (GWs), generated by the thunderstorm itself. Indeed, in the Intertropical Convergence Zone (ITCZ), convective clouds are a primary source of GWs. As the cloud extends vertically and the convective turret reaches the tropopause, a large spectrum of gravity waves is produced. Their wavelength varies between 5 and $50 \mathrm{~km}$, with periods between 10 and $60 \mathrm{~min}$ (Lane and Moncrieff, 2008). Gravity waves are amplified with increasing altitude, interacting in different ways with the background wind field. A number of works (e.g., Lane and Clark, 2002; Lane and Reeder, 2006) show that GWs generated by tropical MCS can propagate very efficiently into the stratosphere. Under specific assumption, high-frequency GW generated by MCS can propagate in the troposphere, upward and opposite to the direction of the storm motion (Fovell et al., 1992), and promote new cloud formation. For instance, using a 2-D nonhydrostatic cloud model constrained by the TOGA COARE (Tropical Ocean and Global Atmosphere Coupled Ocean-Atmosphere Response Experiment) campaign data over the equatorial western Pacific, Shige and Satomure (2001) explain the generation of tropical shallow convection by the action of high-frequency gravity waves. As HFGW are expected to rapidly lose energy trough vertical propagation into the middle atmosphere, a mechanism for trapping their energy is needed. In the case of Shige and Satomure (2001), the waves were ducted in the troposphere below an unstable layer (containing a critical level), with a Richardson number lower than 0.25 , triggering new convection ahead of a more slowly spreading cold pool. Vertical and horizontal storm motion as well as latent heating and cooling can excite gravity waves hydrostatically through mass redistribution, but (as this work suggests) there may be nonhydrostatic and infrasonic effects on surface pressure as well. 


\subsection{Strategy and purposes}

The goal of this work is to analyze in detail the development of a tropical deep convective cloud, the boundary-layer evolution accompanying the convective event and its cold-pool outflow. At the same time, we aim to provide further evidence that cold pool propagation is a leading factor in producing high-frequency surface pressure disturbances, as observed beneath tropical thunderstorms. To address this issue, we compare WRF numerical simulations with in situ ground measurements.

The development of the IMS (International Monitoring System) network, for a constant verification of the CTBT (Comprehensive Nuclear-Test-Ban Treaty), affords the opportunity to explore accurate and permanent observations of atmospheric acoustic signals from 60 infrasound stations homogeneously distributed over the globe. This network is part of the ARISE 2012-2015 (Atmospheric dynamics Research InfraStructure in Europe) project, funded by the European Commission with the aim to coordinate, integrate and optimize different infrastructures (e.g., airglow, lidar, infrasound stations, forecasting modeling, etc.) in order to provide atmospheric observations from the troposphere to the mesosphere. Each station consists of an array of four or more microbarometers (over an area of $1-9 \mathrm{~km}^{2}$ ) and measures the azimuthal angle and horizontal phase velocity of propagating waves. Waves referred to as infrasonic cover sounds above $0.001 \mathrm{~Hz}$ and up to $20 \mathrm{~Hz}$. IMS stations are sensitive to infrasonic signals in the range between 0.01 and $5 \mathrm{~Hz}$, and can detect gravity waves with an amplitude response of several $\mathrm{Pa}$ after correction. They have been used for different research purposes, ranging from earthquake (Le Pichon et al., 2003; Garces et al., 2005), volcano (Evers and Haak, 2001) and hurricane monitoring (Hetzer et al. 2008) to atmospheric dynamics studies. Here, we make use of surface pressure signals acquired by IMS station IS17 in the Ivory Coast, at $6.670^{\circ} \mathrm{N}$, $4.850^{\circ} \mathrm{W}$, close to the ITCZ.

Numerical simulations are performed using the Weather Research and Forecasting model (WRF; Skamarock et al., 2008) version 3.4.1 (released on 16 August 2012), which is able to explicitly resolve convective atmospheric motion due to its high frequency and small-scale 3-D motions. The possibility of running the model in a 2-D idealized configuration offers the unique possibility to perform simplified experiments and analyze cloud dynamics at different spatial scales, controlling external parameters as wind shear, orography, temperature and humidity profile. Idealized numerical experiments are designed to be, although simple, relatively close to a tropical environment. One may wonder how well this simplified approach can reproduce the dynamic structure of a real system. The fidelity of 2-D models in representing three-dimensional convection is still an open question (Moeng et al., 2004; Petch et al., 2008). To test the model's ability to correctly simulate atmospheric dynamics in the case of deep convection, we then perform a 3-D simulation, guided by ECMWF (European Centre for Medium-Range Weather Forecasts) reanalysis data of horizontal wind speed, temperature and humidity (referred to as a "real" case). Results are then compared with those obtained in the 2-D idealized case and with surface time records measured at station IS17.

The paper is organized as follows. First, we provide an overview of tropical deep convection and its physical parametrization (Sect. 2). Second, we present general information about the station IS17 and the WRF model (Sect. 3), describing in detail the numerical experimental setup (Sect. 4). Results from idealized and real model simulations are then presented, compared to in situ observations (Sect. 5) and interpreted, and finally conclusions are discussed (Sect. 6).

\section{Atmospheric convection}

\subsection{Overview}

A convective cell is formed by a column of positively buoyant ascending air, with compensating subsidence and represents the main mechanism responsible for storm formation. Its diameter and vertical extent vary between 5 and $15 \mathrm{~km}$, while its lifetime ranges from 15 to $60 \mathrm{~min}$. Convective cells can be isolated or organized in a mesoscale convective system. MCSs consist of groups of cumulonimbi joined together by a common stratiform anvil (Beucher, 2010). In the vertical ascending updraft, low-level air from the PBL becomes colder with increasing altitude. As water vapor condenses, it releases latent heat that increases the temperature and buoyancy of surrounding air (warm bubble) and further sustains convective dynamics. Warmer air is lifted upward, creating a local depression of pressure below. The convective cloud that consequently forms from water vapor condensation develops vertically until it reaches the base of the stratosphere. Beyond this altitude, a strong temperature inversion quickly slows the unstable ascent, preventing any further substantial increase in cloud-top height. The subsiding downdraft is enhanced by the weight of precipitating water load. Hitting the ground, the more stable cold pool spread outs under the warmer and moister PBL, which is lifted up, becoming rapidly unstable and generating new updrafts. In this way, strong instabilities can arise at the cold pool's boundary. These instabilities can initiate new convective events, processes that may occur repeatedly throughout the day.

Tropical convection regulates large-scale circulation, such as the Hadley and Walker circulations, and can influence the stratosphere, generating gravity waves. The proper representation of tropical convection in numerical models is an open issue, responsible for the largest uncertainties in present meteorological forecasts. In tropical regions, trade winds develop within $30^{\circ} \mathrm{N}, 30^{\circ} \mathrm{S}$. Over the ocean, they transport large quantities of momentum, latent heat and moisture into the ITCZ. This convergence zone is an almost continuously 
cloudy region, principally made of cumulonimbus clouds, associated with strong precipitating events and convective dynamics (generally defined as "deep convection", as it extends from the PBL to the tropopause). Tropical West Africa is characterized by the convergence of two air masses of different nature, one coming from the southeast (the Southern Hemisphere, SH, monsoon) and carrying humid air, and another from the northeast, made of relatively warm and dry air from the Sahara. From October to March, the surface wind (at $950 \mathrm{hPa}$, about $600 \mathrm{~m}$ altitude) from North Africa is relatively strong and converges with the $\mathrm{SH}$ monsoon over the Ivory Coast. From April, northerly winds weakens considerably and the monsoon penetrates inland over West Africa (turning SW as it passes the coastline). At higher altitude (at $750 \mathrm{hPa}$, about $2.5 \mathrm{~km}$ ), the wind field shows an almost constant easterly advection (Costantino and Bréon, 2013). The Ivory Coast is located between 4 and $11^{\circ} \mathrm{N}$ and resides slightly south of the effective convergence zone in $\mathrm{NH}$ summer, at approximately $15^{\circ} \mathrm{N}$. Atmospheric instability is triggered mostly by the SH monsoon and enhanced further by the strong temperature and humidity contrast between the moist and cold ocean surface to the south, and the arid and warm Sahel region to the north. The southern part of the Ivory Coast (including station IS17) is characterized by a strong rainy season during the summer and, to a lesser extent, from September to October.

\subsection{Theoretical background}

Together with classical thermodynamical variables, as temperature, pressure and density, a natural parameter to study density currents is the atmospheric buoyancy, $B\left[\mathrm{~m} \mathrm{~s}^{-2}\right]$. It defines the time variation of air parcel vertical velocity, $w_{\mathrm{p}}$, and can be calculated as (Tompkins, 2001)

$B=\frac{D w_{\mathrm{p}}}{D t}=g \frac{\theta_{\mathrm{v}}-\bar{\theta}_{\mathrm{v}}}{\bar{\theta}_{\mathrm{v}}}$,

where $g\left[\mathrm{~m} \mathrm{~s}^{-2}\right]$ is the gravitational acceleration and $\theta_{\mathrm{v}}[\mathrm{K}]$ the virtual potential temperature. The concept of virtual is adopted to modify the potential temperature of a moist air mass to include the thermodynamic effect of water vapor in the dry-air equation of state. As moist air is lighter than dry air (vapor is less dense than oxygen and nitrogen), virtual temperature is the temperature to which a parcel of dry air must be heated in order to reach the same density as a parcel of moist air at the same pressure. According to Emanuel (1994), virtual potential temperature can be expressed as

$\theta_{\mathrm{v}}=\theta\left(1+0.608 q_{\mathrm{v}}-q_{\mathrm{cl}}-q_{\mathrm{r}}\right)$,

where $\theta[\mathrm{K}]$ is the potential temperature and $q_{\mathrm{v}}, q_{\mathrm{cl}}$ and $q_{\mathrm{r}}$ are the water mixing ratio of vapor, cloud condensate and rain, respectively. The overbar in (1) represents the horizontal domain average at a given altitude. As unsaturated air ascends adiabatically, $\theta_{v}$ is conserved.
When water vapor condenses, $q_{\mathrm{v}}$ decreases and the latent heat released in the vapor-to-liquid phase transition augments the potential temperature of an air parcel according to

$\frac{\mathrm{d} \theta}{\theta}=\frac{-L_{\mathrm{vl}}(T)}{c_{p}\left(q_{\mathrm{v}}\right) T} \mathrm{~d} q_{\mathrm{v}}$

where $T[\mathrm{~K}]$ is the temperature, $L_{\mathrm{vl}}\left[\mathrm{J} \mathrm{kg}^{-1}\right]$ is the latent heat (function of temperature) and $c_{p}\left[\mathrm{~J} \mathrm{Kkg}^{-1}\right]$ is the specific heat (function of water vapor mixing ratio). Although an analytic solution is not possible, Eq. (3) can be easily solved assuming that (1) $c_{p}$ and $L_{\mathrm{vl}}$ are constant and (2) $\left(L_{\mathrm{vl}} / c_{p} T\right)$ $\mathrm{d} q_{\mathrm{v}}=\mathrm{d}\left(L_{\mathrm{v} l} q_{\mathrm{v}} / c_{p} T\right)$. In that case (Yau and Rogers, 1989)

$\theta_{\mathrm{e}}=\theta \exp \left(\frac{L_{\mathrm{vl}} q_{\mathrm{v}}}{c_{p} T_{\mathrm{sp}}}\right) \approx \theta \exp \left(2675 \frac{q_{\mathrm{v}}}{T_{\mathrm{sp}}}\right)$,

where $T_{\mathrm{sp}}$ is the parcel temperature at its condensation point (traditionally called the lifting condensation level, LCL). The quantity $\theta_{\mathrm{e}}$ is the equivalent potential temperature, conserved in moist adiabatic processes. It represents the potential temperature of an air parcel, when all the water is condensed, and is a good proxy to characterize the moist static instability of air in the tropics. In this work, we will make use of a more accurate formulation of $\theta_{\mathrm{e}}$ than Eq. (4) in the case of high humidity, from Bolton (1980).

Since mass is conserved, ascending convective mass fluxes due to positive buoyancy are often compensated for by subsidence. Although subsidence may occur at much smaller vertical velocities (on the order of $10^{-2} \mathrm{~m} \mathrm{~s}^{-1}$ ) than turbulent cloud dynamics (on the order of some $\mathrm{ms}^{-1}$ ), part of the downward flux generally occurs with the same magnitude as ascending turbulence, when buoyancy becomes negative. Equations (2) and (4) show that negative buoyancy may be enhanced by (1) the weight of liquid water of cloud condensate and precipitation, as the term $-g\left(q_{\mathrm{cl}}+q_{\mathrm{r}}\right)$ is always negative, and (2) the cooling effect of liquid water evaporation (or fusion and sublimation, in the case of solid water). To a first approximation, a temperature variation of $1 \mathrm{~K}$ (or, alternatively, a water mixing ratio of $3 \mathrm{~g} \mathrm{~kg}^{-1}$ ) induces an upward (or downward) vertical acceleration equal in magnitude to $0.03 \mathrm{~m} \mathrm{~s}^{-2}$ (Beucher, 2010). The ascending air may then reach enormous vertical velocity, on the order of $30 \mathrm{~m} \mathrm{~s}^{-1}$ (after $15 \mathrm{~min}$ ) and up to $50 \mathrm{~m} \mathrm{~s}^{-1}$, which can create a substantial overshoot beyond the level of neutral buoyancy when approaching the tropopause or penetrating the lower stratosphere.

\section{Instrumentation and numerical model}

\subsection{Station IS17}

Station IS17 is situated at $6.670^{\circ} \mathrm{N}, 4.850^{\circ} \mathrm{W}$, about $200 \mathrm{~km}$ away from the coast line, at an altitude of approximately $150 \mathrm{~m}$. Its geographical position is indicated by a red square 


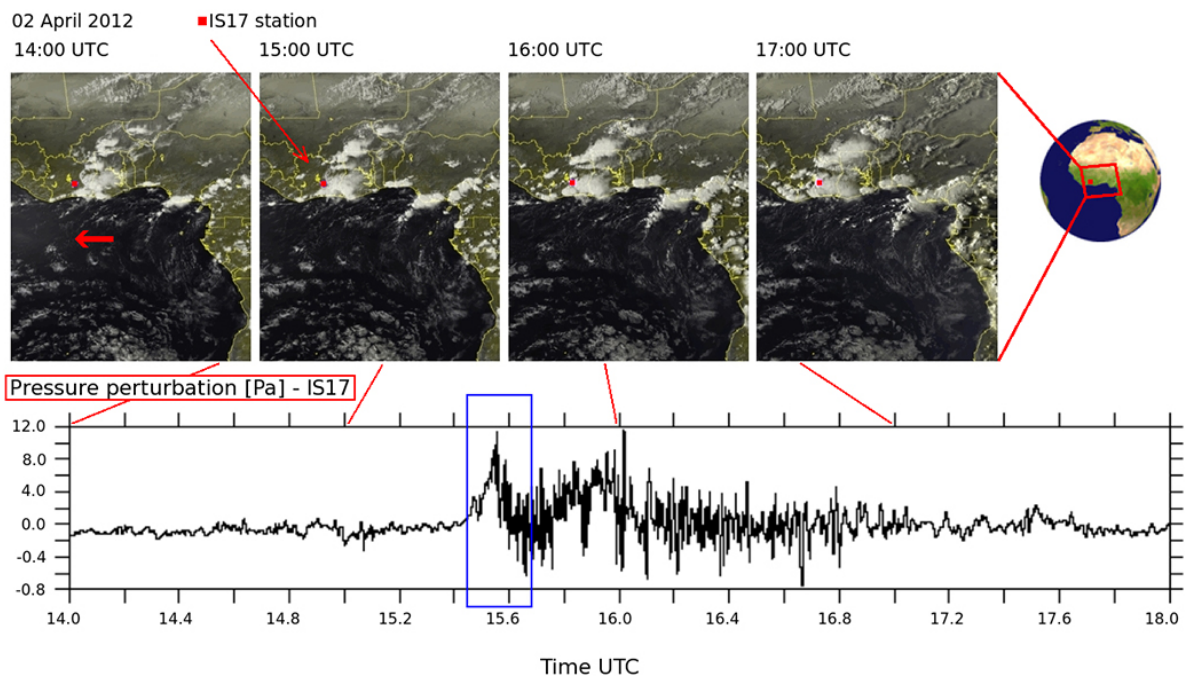

Fig. 1. Top image: true-color satellite images of West African region on 2 April 2012, at 14:00, 15:00, 16:00 and 17:00 UTC. Data are provided by EUMETSAT and acquired by the geostationary meteorological satellite METEOSAT9. National borders are reported in yellow. The position of station IS $17\left(6.670^{\circ} \mathrm{N}, 4.850^{\circ} \mathrm{W}\right)$ is indicated by a red square symbol. The main direction of cloud motion is shown by the easterly red arrow. On the upper-right side of the figure, a red square indicates the area of Earth that is shown in the larger images. Bottom image: filtered surface pressure anomaly [Pa], retrieved by the microbarometer of infrasound station IS17, plotted as a function of time. Anomaly is defined as the difference between local pressure and a constant offset.

symbol in Fig. 1, showing true-color satellite images of West Africa acquired by METEOSAT9 and provided by EUMETSAT (European Organisation for the Exploitation of Meteorological Satellites). Station IS17 is located very close to Lake Kossou (yellow contours), next to the savanna's southern boundary, which almost entirely covers the northern part of the Ivory Coast. South of IS17, the topography is very smooth, with no major reliefs. Terrain is characterized by tropical forest, croplands, grazing and marsh. Such a large variety of ground types can be a relevant source of error in model simulations, as water content and surface friction can vary significantly from one soil to another. Station IS17 consists of four microbarometers (indicated in Fig. 2) that record surface pressure signals with a sampling time of $0.05 \mathrm{~s}$ (in the $0.01-5 \mathrm{~Hz}$ frequency range). The sounders have a very fine sensitivity of $1 \mathrm{mPa}$, a large dynamic range of $80 \mathrm{~dB}$, and are equipped with an acoustic filter system (made of microporous hoses), which reduces surface wind noise (Alcoverro and Le Pichon, 2005). For retrieved frequencies lower than $0.01 \mathrm{~Hz}$, the filter produces an amplitude reduction of about $20 \mathrm{~dB}$ per decade. The IS17 site is equipped with a meteorological station that measures temperature, pressure, wind speed and direction with a temporal sampling of $1 \mathrm{~s}$.

\subsection{WRF}

The Advanced Research WRF (ARW) model, created by the National Center for Atmospheric Research (NCAR) in 2000 , is described in detail in terms of its governing equations, parametrization schemes and numerical methods in
Skamarock et al. (2008). WRF resolves six equations (Euler's motion equations, the first principle of thermodynamics, the continuity equation and the perfect gas law) to calculate vertical $(W), x$ horizontal $(U)$ and $y$ horizontal $(V)$ wind components, temperature, mass and pressure, respectively. Euler's equations are fully compressible (sound waves are retained) and nonhydrostatic. The vertical motion is resolved in a terrain-following sigma-pressure system, ranging from 1 to 0 between the surface and the top of the atmosphere. WRF uses a third-order (for linear equations) and a second-order (for nonlinear equations) Runge-Kutta integration scheme to calculate a first estimate of prognostic variables. Separate treatment of sound waves is required owing to their fast timescale, not their meteorological relevance or otherwise. For this purpose, WRF uses a second integration scheme, with a much smaller integration time step, that refines the value of prognostic variables previously calculated. ARW is well suited for a numerous of advanced scientific atmospheric applications. Its spatial grid scale spectrum spans from a few tens of meters, suitable for performing large eddy simulations (LES), to hundreds of kilometers, suitable for mesoscale system simulations. In particular, the two-way nesting allows for feedback between small-scale turbulence and mesoscale dynamics. The ability of WRF to resolve small-scale boundary layer turbulent dynamics has been acknowledged by recent LES studies of Moeng et al. (2007), Wang et al. (2009) and Lenaerts et al. (2009). 
IS17 - Sensor position

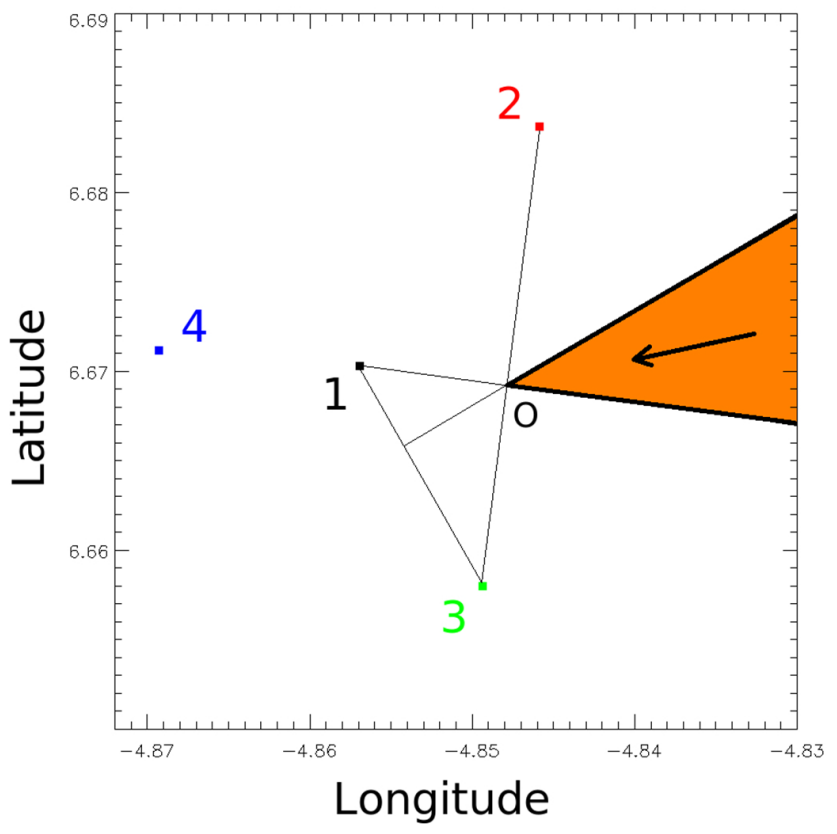

Fig. 2. Geographical position of the four microbarometer sensors of station IS17. The region within the orange area indicates an approximate estimate of the possible arrival angles, with respect to the point $\mathrm{O}$, of the pressure disturbance wave (assuming a plane wave), according to the temporal order of pressure peak detection (recorded first at station 2 and then at 3,1 and 4).

\section{Experimental setup}

\subsection{Idealized simulation}

In the idealized case, we use WRF as a cloud-resolving model (CRM) with no subgrid parametrization of boundary layer and convective cloud scheme. To fully resolve atmospheric turbulent dynamics, horizontal $(\Delta x)$ and vertical $(\Delta z)$ grid spacings are relatively small, with smaller $\Delta z$ in the troposphere. Horizontal resolution is constant, $\Delta x=250 \mathrm{~m}$, while $\Delta z$ is stretched vertically, increasing exponentially from approximately $140 \mathrm{~m}$ (between the surface and $15.5 \mathrm{~km}$ altitude) up to $2700 \mathrm{~m}$ (at model top, set at $38.5 \mathrm{~km}$ altitude). The computational domain size is threedimensional and composed of 1499 grid points along the longitudinal $x$ direction (real horizontal geometrical size of $375 \mathrm{~km}$ ), 3 grid points in the $y$ direction, and 160 vertical levels. The 2-D solution is computed by integrating the 3-D model over the $y$ direction. As no initial $y$-dependent perturbation is present, the solution remains independent from $y$ and the 2-D field for display is one of the three $x-z$ planes.

We use open conditions at both lateral boundaries and put a $10 \mathrm{~km}$ depth Rayleigh absorbing layer (with a relatively high damping coefficient, equal to $0.1 \mathrm{~s}^{-1}$ ) at model top in order to reduce wave reflection effects. Eddy coefficients for subgrid thermal and (horizontal and vertical) momentum diffusion are estimated from the turbulent kinetic energy (TKE) 1.5 order equation (vertical subgrid diffusion is called by the code only if no boundary layer scheme is present, as in this case). Microphysics are parametrized using the classical warm rain scheme (Kessler, 1969), typical of cloud modeling studies; they only include water vapor, cloud water and rain. The processes taken into account are the production, fall and evaporation of rain; the accretion and auto-conversion of cloud water; and the production of cloud water from condensation. It has been shown that neglecting ice-phase microphysics makes no significant difference in the life cycle of a mesoscale convective system, nor in its propagation speed, total precipitation and evaporative cooling both in the stratiform and convective regions (Tao and Simpson, 1989). The main difference lies in the fact that, without ice phase, heavy precipitation (larger than $30 \mathrm{mmh}^{-1}$ ) increases significantly and stratiform cloud depth is smaller. To better capture density current sensitivity to environmental parameters, we build up a simplified framework, where variables linked to other factors than real physics (such as model dynamics, turbulence, numerical and microphysics schemes, etc.) remain unaltered or are neglected (where possible). In particular, Coriolis force is switched off (spatial scale is reduced) and both shortwave and longwave radiation schemes are not considered (assuming that time integration and cloud fraction are sufficiently small to ignore radiative feedback from atmospheric heating on humidity and cloud life cycle).

When the simulations start, the wind field is set to zero at every altitude level. The atmosphere is at rest, horizontally stratified over an idealized surface with flat topography. Environmental vertical profiles of potential temperature and water vapor mixing ratio are imposed externally. In the benchmark simulation, the initial potential temperature at the surface is equal to $300 \mathrm{~K}$ and increases linearly with altitude, with a lapse rate $(\Gamma=-\mathrm{d} T / \mathrm{d} z)$ equal to $3.5 \mathrm{~K} \mathrm{~km}^{-1}$. To test the effects of more stable and less stable environments, sensitivity experiments use respectively negative and positive lapse rate increments, $\Delta \Gamma$, of $-1 \%,-0.5 \%,+0.5 \%,+1.0$, $+1.5 \%$ and $+5 \%$. Beyond the temperature inversion altitude level $(15.5 \mathrm{~km})$, the temperature profile is provided by ECMWF reanalysis data for the Ivory Coast on 2 April 2012 at 12:00 UTC. The initial vertical profile of water vapor mixing is that used by Lane and Reeder (2001) and was measured by Keenan et al. (2000) during the Maritime Continent Thunderstorm EXperiment (MCTEX) over the Tiwi Islands, Australia:

$q_{\mathrm{v}}(z)=19.2 \exp \left(-[z / 3100]^{1.5}\right)$,

where $q_{\mathrm{v}}$ is expressed in $\mathrm{g} \mathrm{kg}^{-1}$ and $z$ is the altitude in meters. Convection is triggered by a bidimensional (along $z$ and $x$ axes) warm bubble with a maximum amplitude of $2 \mathrm{~K}$, horizontal radius of $5 \mathrm{~km}$, vertical radius of $1.5 \mathrm{~km}$ and centered 
at $1.5 \mathrm{~km}$ altitude. The model simulation is integrated over $3 \mathrm{~h}$, with a time step of $2 \mathrm{~s}$.

\subsection{Real simulation}

The model domain is composed of three nested grids, with an increasing horizontal resolution of 27,9 and $3 \mathrm{~km}$, all with the same vertical resolution. Grid 3 (the smallest and finest resolved) contains the whole Ivory Coast region. We use 123 pressure levels, with a Gaussian width stretching of $\Delta z$ that increases from 50 to $500 \mathrm{~m}$ (between the surface and $20 \mathrm{~km}$ ) and thereafter remains constant up to model top (at $54 \mathrm{~km}$ ). Pressure values are provided by ECMWF reanalysis data, averaged over the parent domain and interpolated vertically with a step of $500 \mathrm{~m}$. The integration time step decreases from $30 \mathrm{~s}$ down to 10 and $5 \mathrm{~s}$ (inner grid).

Synoptic ECMWF reanalysis data, provided with a time resolution of $3 \mathrm{~h}$, a horizontal resolution of $1^{\circ}$ and 91 vertical pressure levels, from the ground to $1 \mathrm{~Pa}$ (about $80 \mathrm{~km}$ ), are used to initialize and nudge the main model variables. The nudging is internal to the domain and consists in a simultaneous relaxation of horizontal wind components, temperature and specific humidity, with relaxation times of $3 \times 10^{4} \mathrm{~s}^{-1}$ $(U$ and $V)$ and $1 \times 10^{5} \mathrm{~s}^{-1}$ (temperature and moisture).

Note that for real cases, WRF imposes a default lapse rate rather inappropriate for simulating the stratosphere, with a temperature profile that decreases monotonically with increasing altitude up to the tropopause and is isothermal thereafter. This leads to strong errors when trying to simulate the stratosphere (characterized by a positive thermal gradient between 1 and $3 \mathrm{Kkm}^{-1}$ ) and in particular its upper region, where the deviation between real and calculated temperature can be significantly large, on the order of $50 \mathrm{~K}$. As in Kim et al. (2010), we use a realistic temperature profile obtained by averaging ECMWF data over the region of interest for each pressure level and vertically interpolating to the model grid.

Surface properties such as albedo, emissivity, water content, thermal inertia and surface friction are calculated for each grid from NOAA (National Oceanic and Atmospheric Administration) data, provided at $1 \mathrm{~km}$ resolution. For topography and soil-type information, we make use of the highresolution standard data set of WRF.

A number of physical schemes (for microphysics, radiation, convection, surface layer, land surface, and boundary layer) have been tested and compared with in situ observations from the meteorological station IS17. Results from some sensitivity experiments suggest that physical parametrization has the same importance as nudging. As in Spiga et al. (2008), we use the Eta-Ferrier microphysical scheme, preferred here to the Thompson scheme. It considers vapor, liquid and solid water and allows for the water-ice phase transition. For radiation, the standard WRF scheme at both short- and longwave has been adopted. It is called every 10 min in grids 1 and 2, and every minute in grid 3 (inner one). A cumulus cloud parametrization scheme (CPS) is an essential tool, in coarse-resolution simulations, that allows for control of the moisture content over the region of interest and creates precipitation from water-loaded ascending air masses. Here the Kain-Fritsch (1993) scheme (KF) has been preferred over the Grell and Betts-Miller schemes. The performances of KF have been positively tested in a number of previous works, as in Spiga et al. (2008) and Kim and Chun (2010), to reproduce a typhoon. This CPS includes a cloud model with updraft and downdraft, and considers the effect of detainment and entrainment as well as shallow and deep convection. This last version of KF has been improved for a better simulation of tropical cyclones in the case of weak synoptic forcing. A new convective trigger function (based on the work of Ma and Tan, 2009, and Yu and Lee, 2010) is added to account for the effect of moisture advection in determining the convective parcel's temperature perturbation. Our preliminary tests showed that the Ivory Coast storm fails to develop on 2 April 2012 if moist advection option is turned off, because of the lack of strong wind convergence near the surface. The CPS is applied to grids 1 and 2 , but not to grid 3, where the relatively fine horizontal resolution ( $\Delta x=\Delta y=3 \mathrm{~km}$ ) allows for large cloud dynamics to be explicitly resolve. This CPS only accounts for one single cloud within each grid box and is not adapted to numerical simulations with horizontal resolution smaller than 5-10 km (Molinari and Dudek, 1992). At ground level, as ECMWF reanalysis data are not sufficient to calculate friction velocities and exchange coefficients, we use the simplified MoninObukhov surface layer scheme. The land-surface model is a five-layer scheme used to calculate heat and moisture fluxes over land. It couples surface layer (for atmospheric information), radiation (for radiative forcing), microphysical (for precipitation) and convective schemes together with inner information on land properties and infrared thermal diffusion. Temperature and (land-use- and seasonal-dependent) moisture values are fixed. No explicit vegetation effects are considered. This scheme has been preferred here over the standard WRF scheme (Noah LSM) with four soil layers. However, both schemes reproduce temperature and moisture in good agreement with in situ observations from station IS17. As in Heinrich and Blanchard (2009), vertical sub-grid-scale fluxes due to eddy transport, potential temperature, water mixing ratios and turbulent fluxes of horizontal wind field, within the boundary layer, are calculated using the YSU (Yonsei University scheme) scheme, where the PBL depth is defined by a Richardson number equal to zero.

Preliminary tests have also shown that a Rayleigh damping layer (applied in the top $10 \mathrm{~km}$ of vertical model domain, between 44 and $54 \mathrm{~km}$ ), with a coefficient of $0.2 \mathrm{~s}^{-1}$, relatively well absorbs gravity waves generated by the thunderstorm, preventing strong downward wave reflection at model top. 


\section{Results}

\subsection{Idealized case}

\subsubsection{Temporal evolution}

In this very first step, we explore the evolution of a single-cell convective cloud in the domain, with the benchmark temperature profile $\Gamma=3.5 \mathrm{~K} \mathrm{~km}^{-1}$. As the thermal bubble is symmetric in $x$ and $y$-independent, orography is absent and background flow is at rest, we expect a symmetric evolution about the $x$ axis of all simulated fields. However, small asymmetries (enhanced with finer spatial or temporal resolution) occur at cloud center with increasing time integration, as vertical velocity becomes particularly strong.

Cloud and precipitation formation. After $7.5 \mathrm{~min}$ of time integration $(t=7.5 \mathrm{~min})$, a cloud (defined as the area where the cloud water mixing ratio is larger than $0.1 \mathrm{~g} \mathrm{~kg}^{-1}$ ) forms between 1.5 and $2.2 \mathrm{~km}$ altitude under the thermodynamical forcing produced by the warm bubble. It grows rapidly, and precipitation (water mixing ratio larger than $0.1 \mathrm{~g} \mathrm{~kg}^{-1}$ ) develops $7 \mathrm{~min}$ later. In these very first moments, cloud grows quickly and, at $t=20 \mathrm{~min}$, it extends vertically from 1 to $5 \mathrm{~km}$ altitude. Buoyancy varies from 0 to $0.05 \mathrm{~m} \mathrm{~s}^{-2}$, in the lower-middle part of the cloud, up to $2 \mathrm{~m} \mathrm{~s}^{-2}$, near cloud top. As a consequence, a central updraft forms with high vertical velocities between 10 and $20 \mathrm{~m} \mathrm{~s}^{-1}$ and peak values above $30 \mathrm{~m} \mathrm{~s}^{-1}$ in the upper layers. At the same time, negatively buoyant air just outside the cloud's lateral boundaries produces subsidence. Between 2 and $5 \mathrm{~km}$ altitude, air moves downward along both cloud sides (with downward vertical velocities approaching $-10 \mathrm{~m} \mathrm{~s}^{-1}$ ), while a small divergent horizontal flux forms at cloud top. A horizontally convergent air flow rises in the lower part of the cloud in order to fill the depression created by the evacuation of lifted air through the vertically divergent ascent. Precipitation occurs all along cloud depth but does not reach the surface. It is more intense between 3.4 and $4.5 \mathrm{~km}$ altitude, where precipitation water mixing ratio reaches $6-10 \mathrm{~g} \mathrm{~kg}^{-1}$.

Convective dynamics development. At $t=25 \mathrm{~min}$ (Fig. 3a), cloud top has grown further by approximately $3.5 \mathrm{~km}$ in $5 \mathrm{~min}$ up to $8.5 \mathrm{~km}$ altitude. Within the cloud, air fluxes are directed upward almost everywhere. Vertical wind speed varies from $5 \mathrm{~m} \mathrm{~s}^{-1}$ to slightly less than $15 \mathrm{~m} \mathrm{~s}^{-1}$ from the lower to the upper cloud layer. Part of the horizontally divergent air flux at cloud top turns downward (with a maximum vertical velocity up to $-10 \mathrm{~m} \mathrm{~s}^{-1}$, at $6 \mathrm{~km}$ altitude) and maintains the subsidence. At both cloud sides, subsiding air gives rise to a convective circulation system together with the rising flow that moves upward along lower boundaries of cloud. At $4-5 \mathrm{~km}$ altitude, the ascending air is forced by the subsidence to deviate inward and penetrate into the upper cloud layer. In this way, less buoyant and denser air is efficiently transported from the lower atmosphere toward cloud top. As a consequence, a small region of negative buoyancy forms between 5 and $7 \mathrm{~km}$ altitude, corresponding to the largest rain water mixing ratio $\left(6-11 \mathrm{~g} \mathrm{~kg}^{-1}\right)$. This is just below the uppermost and unstable cloud layer (7-8.5 km altitude), where potentially warm air (as is) attains a density depression of $20 \mathrm{~g} \mathrm{~m}^{-3}(-3 \%)$ with respect to the environment, and resulting buoyancy increases up to $0.25 \mathrm{~m} \mathrm{~s}^{-2}$. Precipitating water decreases with decreasing altitude down to very small values at cloud base $\left(\sim 1 \mathrm{~g} \mathrm{~kg}^{-1}\right)$ and almost zero at the surface.

A $t=30 \mathrm{~min}$ (Fig. 3b), cloud top reaches an altitude of $11.5 \mathrm{~km}$, with a horizontal extent of about $6 \mathrm{~km}$. At both cloud sides, convective dynamics is well established. The updraft rising from cloud's lower boundaries (i.e., the ascending branch of the convective cell) has largely increased in magnitude with respect to $5 \mathrm{~min}$ before; it now converges within the cloud upper layer at approximately 6-7 km altitude (breaking the cloud system into two subclouds). The higher subcloud (between 7 and $11.5 \mathrm{~km}$ altitude) is characterized in its lower part by negative buoyancy, down to $-0.1 \mathrm{~m} \mathrm{~s}^{-2}$ (associated with a negative temperature perturbation of $-2 \mathrm{~K}$, positive density perturbation up to $4 \mathrm{~g} \mathrm{~m}^{-3}$ and large rain water mixing ratio), and near cloud top by positive buoyancy, larger than $1 \mathrm{~m} \mathrm{~s}^{-2}$ (associated with positive temperature perturbation of $+4 \mathrm{~K}$ and negative density perturbation down to $-10 \mathrm{~g} \mathrm{~m}^{-3}$ ). However, vertical velocity is largely positive almost everywhere, even in negatively buoyant regions. In the lower subcloud (below $7 \mathrm{~km}$ altitude), the large thermodynamic instability (induced by a temperature perturbation up to $+4 \mathrm{~K}$ and a density depression of more than $20 \mathrm{~g} \mathrm{~m}^{-3}$ ) increases the buoyancy above $0.1 \mathrm{~ms}^{-2}$. The resulting updraft has a vertical velocity that varies between 10 and $15 \mathrm{~m} \mathrm{~s}^{-1}$. Just outside the subcloud left and right boundaries, a narrow (2-3 km wide) downdraft forms, moving at about $-5 \mathrm{~m} \mathrm{~s}^{-1}$. Hitting the ground, it spreads out radially up to $6 \mathrm{~km}$ away from storm center and converges with the cloud inflow, creating a curl. This mechanism reorganizes low-level circulation between 0 and $2 \mathrm{~km}$ altitude and forms a secondary convective cell (at both cloud sides) that will rapidly grow in size.

Generation of the density current. At $t=35 \mathrm{~min}$ (Fig. 3c), the central cloud updraft below $6 \mathrm{~km}$ (induced by the warm bubble) has almost completely vanished and is substituted by a descending air column, with vertical velocities of $-5 \mathrm{~m} \mathrm{~s}^{-1}$. This produces a surface outflow that is strong enough to increase the size of the secondary convective cell (up to $7 \mathrm{~km}$ altitude). Because of its high positive buoyancy, the lower subcloud (mostly evaporated below $6 \mathrm{~km}$ ) moves upward by about $2-3 \mathrm{~km}$, while cloud top rises by only $1 \mathrm{~km}$ (attaining its maximum altitude of $12.5 \mathrm{~km}$ ). As a consequence, cloud top is compressed and the anvil starts to develop horizontally at an altitude of $9-10 \mathrm{~km}$. The upper cloud layer, above $6 \mathrm{~km}$, is now characterized by cold, denser air above $(B<0$ from 9 to $12.5 \mathrm{~km}$ ) and warm, less dense air below $(B>0$ from 6 to $9 \mathrm{~km})$. The positively buoyant air mass, referred to as PB1, has an elevated positive vertical velocity in its central part and a high water load (up to $11 \mathrm{~g} \mathrm{~kg}^{-1}$ of rain water mixing 

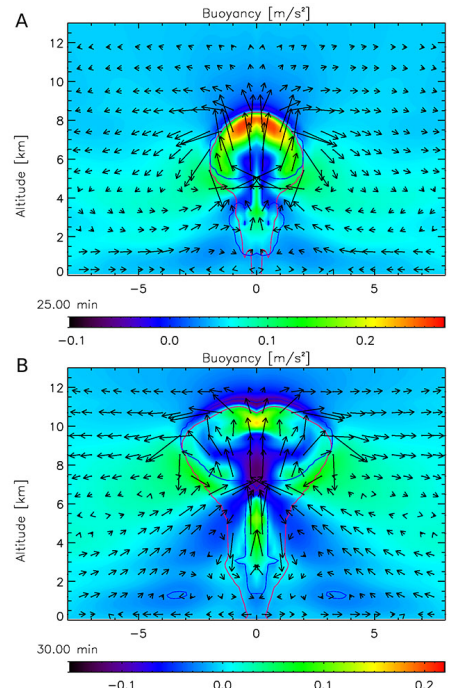

C

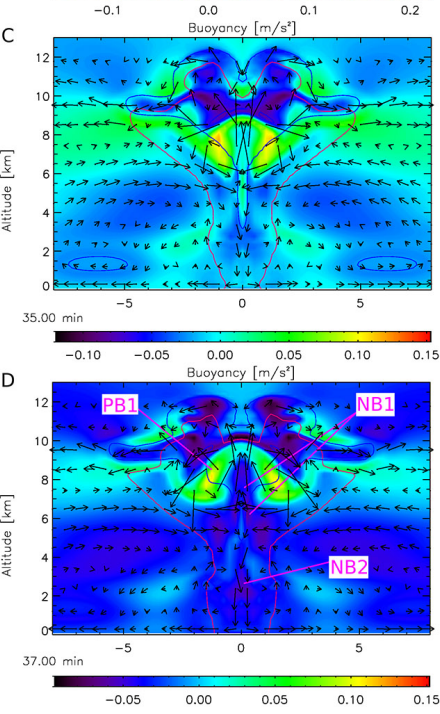

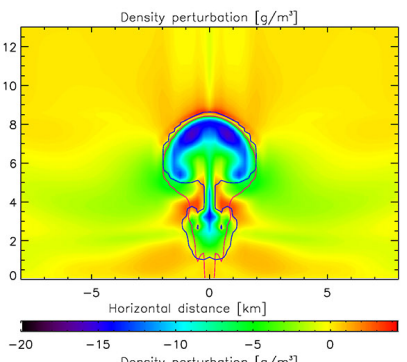
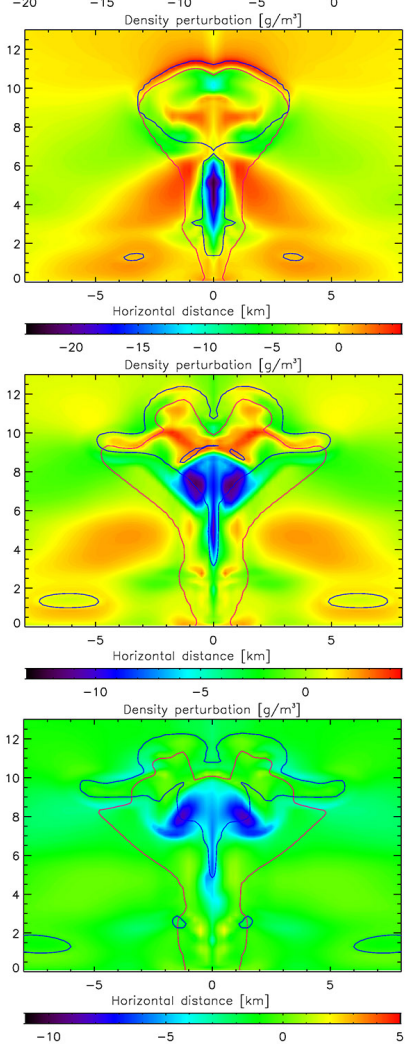
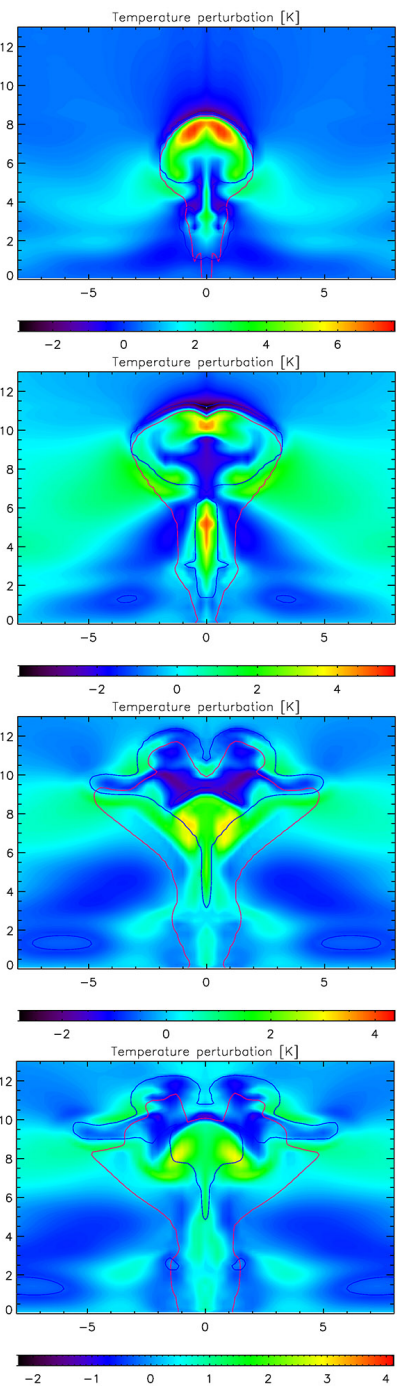
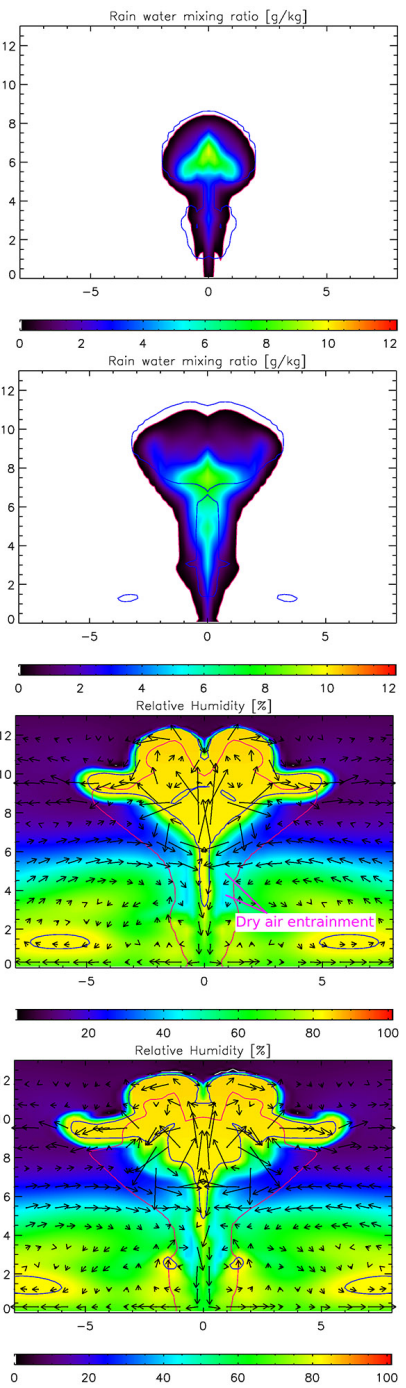

Fig. 3. Idealized benchmark simulations $\left(\Gamma=3.5 \mathrm{~K} \mathrm{~km}^{-1}\right)$. Vertical cross section, between 0 and $13 \mathrm{~km}$ altitude, of buoyancy [ms $\left.\mathrm{m}^{-2}\right]$, density perturbation $\left[\mathrm{g} \mathrm{m}^{-3}\right.$ ], temperature perturbation $[\mathrm{K}]$ and rain water mixing ratio $\left[\mathrm{g} \mathrm{kg}^{-1}\right]$ at $t=25$ (A), 30 (B), 35 (C), 37 (D), 40 (E) $42(\mathbf{F}), 45(\mathbf{G}), 50(\mathbf{H})$ and 55 (I) min. Note that color scale is different for each image. Perturbation is defined as the difference between local value and domain average, at fixed altitude. Wind vectors are overplotted on first image. The length of an arrow is proportional to wind intensity ( $1 \mathrm{~km}$ in spatial reference system scale is equal to $5 \mathrm{~m} \mathrm{~s}^{-1}$ ).

ratio) at about $8 \mathrm{~km}$ altitude. Below $6 \mathrm{~km}$, convective dynamics within the central downdraft transports large amounts of cold, dry and negatively buoyant air. This is clearly shown in the vertical cross section of RH. According to wind velocity vectors, air masses with relative humidity $20 \%$ lower than surrounding air (indicated in light blue) are advected within the precipitation path (between 3 and $5 \mathrm{~km}$ ) from outer and higher regions (at 5-6 km altitude) by the convective circulation. The intrusion of dry (cold and negatively buoyant) air, at both cloud sides between 5 and $7 \mathrm{~km}$, increases at $t=37 \mathrm{~min}$ (Fig. 3d). At the converging point, this air mass (hereafter referred to as NB1) is partly transported upward (by the large positive vertical velocities at PB1 base, up to $9 \mathrm{~km}$ altitude) and partly downward. In the downdraft core, coincident with precipitation field, negative buoyancy is probably further enhanced by the weight of water load (particularly below $6 \mathrm{~km}$ ), and peaks of negative buoyancy also occur in the lower atmosphere. That is the case of the negatively buoyant air mass shown in Fig. 3d, between 2 and $5 \mathrm{~km}$, and indicated as NB2. Moving downward, NB2 undergoes an adiabatic increase in temperature and density. The presence of dry air strengthens the temperature enhancement with respect to moister regions at the downdraft's boundaries and outside. This explains the positive temperature (and density) anomaly shown in Fig. $3 \mathrm{e}$ between 0.5 and $2 \mathrm{~km}$, at $t=40 \mathrm{~min}$. The vertical displacement of NB2 by $2-3 \mathrm{~km}$ in $3 \min$ (from $t=37$ and $40 \mathrm{~min}$ ) is consistent with observed vertical velocities up to $-17 \mathrm{~m} \mathrm{~s}^{-1}$ (approximately $1 \mathrm{~km} \mathrm{~min}^{-1}$ ). Below $0.5 \mathrm{~km}$, 

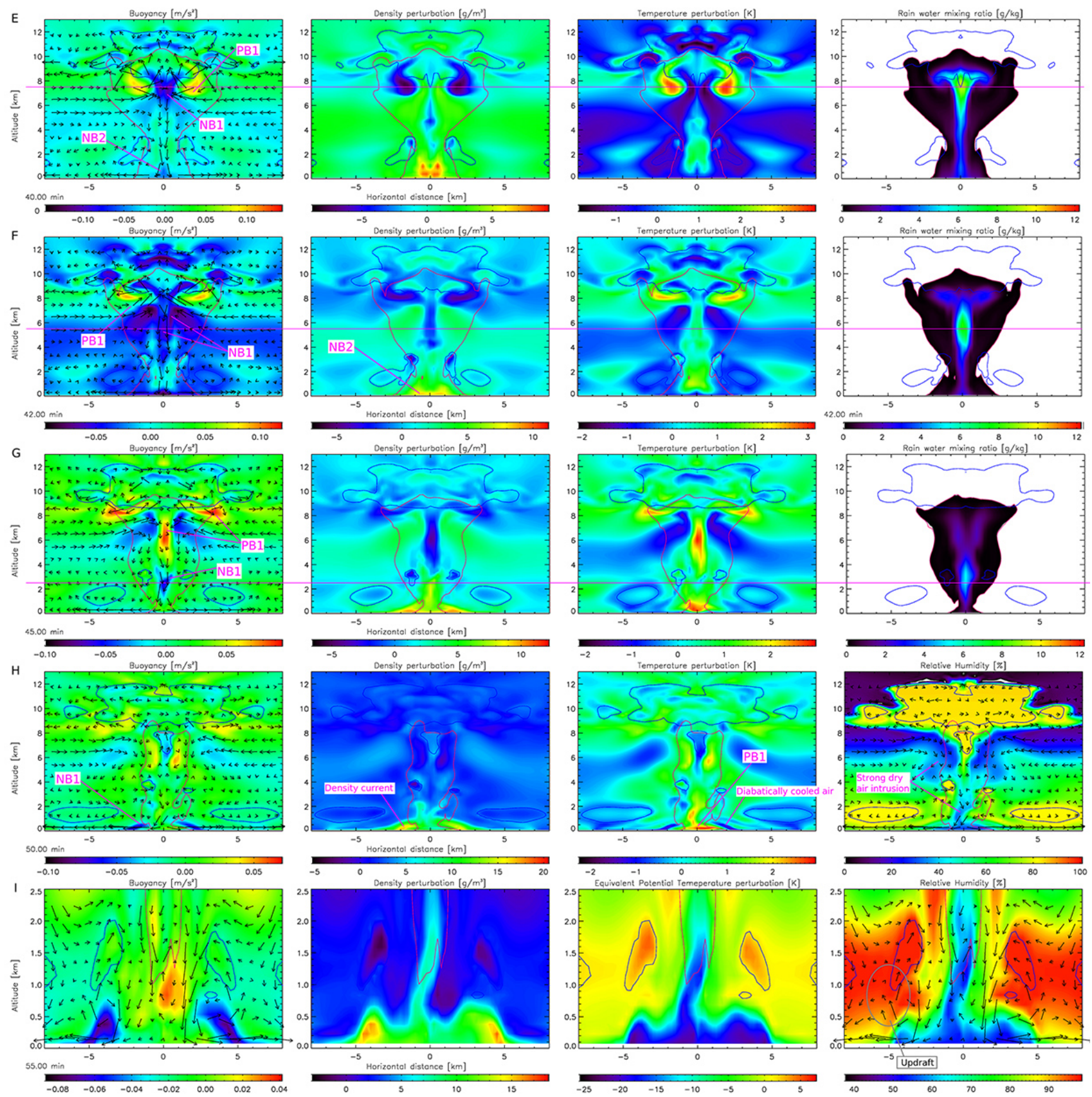

Fig. 3. Continued.

surface temperature is warm enough to impose a diabatic heating that evaporates large amounts of rain water, leading to a sudden decrease in air temperature. As a consequence, a first surface density perturbation (up to $+10 \mathrm{~g} \mathrm{~m}^{-3}$ ) occurs after $t=42 \mathrm{~min}$ (Fig. 3f).

Cold pool propagation. It is interesting to note that, starting from $t=40 \mathrm{~min}$, the peak of negative buoyancy (NB1) coincides with that of precipitating water mixing ratio, at about $7.5 \mathrm{~km}$. This is stressed by the purple horizontal line, overplotted in Fig. 3f-h. At the same altitude, but further from downdraft center (at its left and right side), there is the warm and positively buoyant PB1 air mass. With increasing time integration, NB1 moves downward, together with the precipitation peak. Their position $(7,5$ and $2.5 \mathrm{~km}$ for $t=40,42$ and $45 \mathrm{~min}$, respectively) is consistent with vertical wind speed, within the downdraft core, of approximately $1 \mathrm{kmmin}^{-1}$. At $t=45 \mathrm{~min}$ (Fig. $3 \mathrm{~g}$ ), PB1 is also injected into the downdraft and advected downward. It lags the colder 
and denser NB1, which reaches the surface at $t=47 \mathrm{~min}$, by about $2 \mathrm{~km}$ (i.e., almost $2 \mathrm{~min}$ ). In the lowest atmospheric levels, the effect of the violent diabatic cooling from rain evaporation generates a strong density increase. At the surface, the resulting air flow propagates outward. At $t=50 \mathrm{~min}$ (Fig. 3h), the density $\left(+20 \mathrm{~g} \mathrm{~m}^{-3}\right)$ and temperature $(-2 \mathrm{~K})$ perturbations at its leading edges $(2 \mathrm{~km}$ away from downdraft center) attain $+20 \mathrm{~g} \mathrm{~m}^{-3}$ and $-2 \mathrm{~K}$, respectively, with buoyancy values down to $-0.08 \mathrm{~m} \mathrm{~s}^{-2}$. Five minutes later, at $t=55 \mathrm{~min}$ (Fig. 3i), these thermodynamic anomalies reach a horizontal distance of $5 \mathrm{~km}$ (at both cloud sides), accompanied by surface wind speeds up to $15 \mathrm{~m} \mathrm{~s}^{-1}$. In the inner part of the outflow, density remains high, while buoyancy and temperature suddenly re-increase as a consequence of PB1 arrival $(t \sim 49 \mathrm{~min})$. This positively buoyant air mass is in fact sensibly warmer (and less water loaded) than NB1. On the other hand, relative humidity remains $20-40 \%$ lower than surrounding air, within the entire region affected by the density perturbation, because of the continuous dry-air entrainment. At $t=60 \mathrm{~min}$, precipitation is completely exhausted, convection is over and the cloud life cycle can be considered finished. An elevated anvil, with a modest cloud water mixing ration not larger than $0.4 \mathrm{~g} \mathrm{~kg}^{-1}$, remains suspended between 9 and $12 \mathrm{~km}$ altitude.

\subsubsection{Density current}

Figure 3 clearly shows the vertical $(600-700 \mathrm{~m})$ and horizontal $(5-7 \mathrm{~km})$ extent - indicated in green and red, respectively - of the density current that propagates within the PBL. At its lateral boundaries, negative buoyancy approaches $-0.08 \mathrm{~m} \mathrm{~s}^{-2}$ (shown by blue and dark blue), the positive density variation increases to $18 \mathrm{~g} \mathrm{~m}^{-2}$ (red) and relative humidity remains below $40-50 \%$. Instead of actual temperature, we report the equivalent potential temperature, which is a good proxy to estimate the moist static stability of tropical air masses. In this case, the negative equivalent potential temperature perturbation, down to -20 and $-25 \mathrm{~K}$ (blue and dark blue), shows that the cold pool is much more stable than the surrounding PBL. Moving outward, the colder air mass is pushed under the warmer and moister subcloud layer, which is lifted up. This mechanism creates strong vertical updrafts, shown by the wind velocity vectors at density current boundaries in Fig. 3i.

Temporal and spatial evolution of disturbances, associated with the density current propagation, are well described by time records retrieved in the lowest atmospheric layer (below $150 \mathrm{~m}$ altitude, hereafter referred to as "surface level") and reported in Fig. 4. The figure shows precipitation water mixing ratio, temperature, relative humidity, density, pressure and horizontal wind speed observations measured at different stations located at 1, 5, 10, 15, 20, 25 and $30 \mathrm{~km}$ away from the storm center (referred to as virtual detection station A, B, C, D, E, F and G, respectively). The sampling time is $10 \mathrm{~s}$. Except for the surface pressure variations (defined as
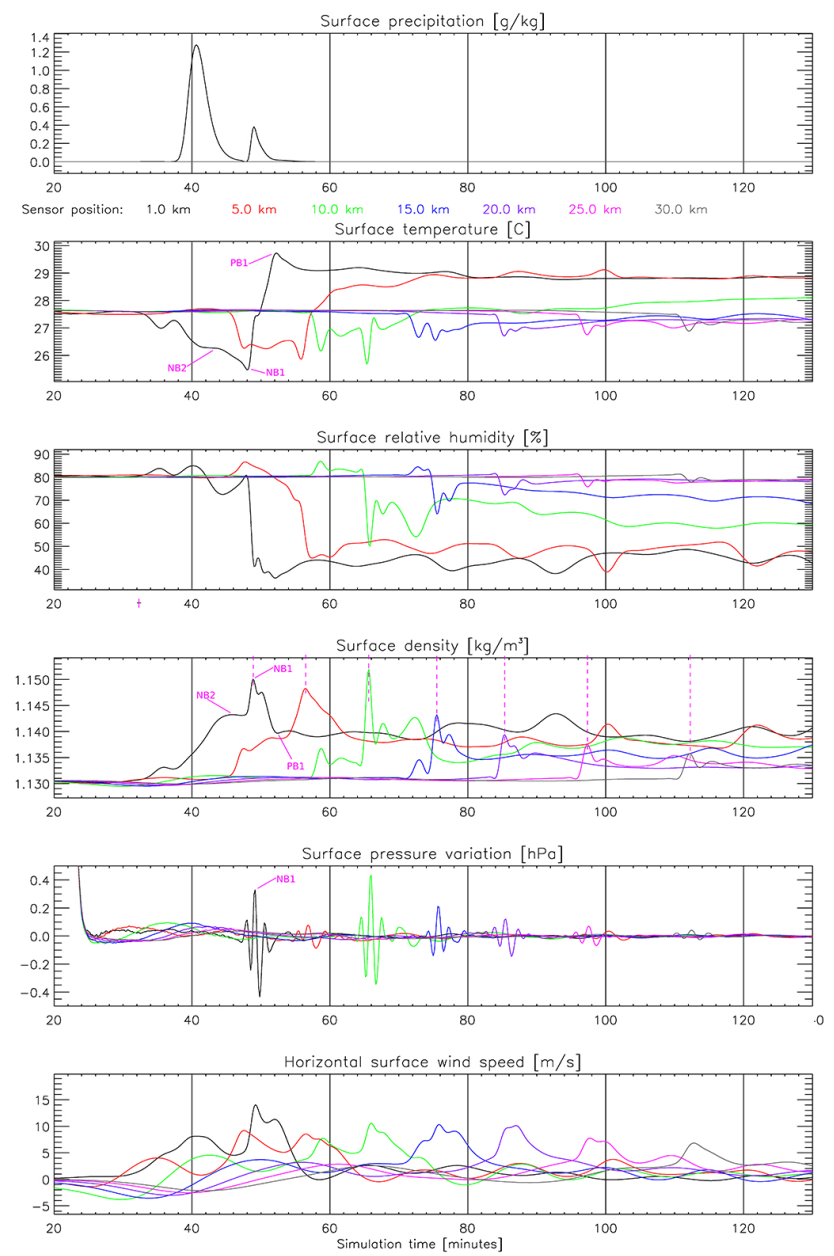

Fig. 4. Idealized benchmark simulation $\left(\Gamma=3.5 \mathrm{~K} \mathrm{~km}^{-1}\right)$. Time records of precipitation $\left[\mathrm{g} \mathrm{kg}^{-1}\right]$, temperature $\left[{ }^{\circ} \mathrm{C}\right]$, relative humidity $[\%]$, density $\left[\mathrm{kg} \mathrm{m}^{-3}\right]$, pressure variation $[\mathrm{Pa}]$ and horizontal $U$-wind speed $\left[\mathrm{ms}^{-1}\right]$ measured in the lowest atmospheric model level (between 0 and $150 \mathrm{~m}$ altitude) and referred to as "surface level". Variation is defined as the difference between observed value and the hydrostatically stable state, calculated by WRF. Line colors identify the different virtual detection stations, situated at a distance of $1 \mathrm{~km}$ (station A, black), $5 \mathrm{~km}$ (B, red), $10 \mathrm{~km}$ (C, green), $15 \mathrm{~km}$ (D, blue), $20 \mathrm{~km}$ (E, dark purple), $25 \mathrm{~km}$ (F, light purple) and $30 \mathrm{~km}$ (G, gray) from domain center.

the pressure difference with respect to a hydrostatically stable state), all other variables are expressed in absolute values. Surface pressure is subjected to long-period oscillations. To retain only short-period variations and isolate the infrasonic part of the pressure signal, we perform a high-pass filtering on time records, with a cut frequency of $0.00683 \mathrm{~Hz}$ (equivalent to a period of about $2.5 \mathrm{~min}$ ).

Just beneath cloud base, surface precipitation occurs after about $30 \mathrm{~min}$ of time integration. This induces a smooth but sudden temperature decrease that rapidly propagates radially, reaching station $\mathrm{A}(1 \mathrm{~km})$ at $t=32 \min (5 \min$ before surface rain occurrence in that point). Starting from $t=37 \mathrm{~min}$, we 
observe a constant decrease in surface temperature that culminates at $t=44 \mathrm{~min}$ (for a total $T$ variation of $-1.2^{\circ} \mathrm{C}$ in $7 \mathrm{~min}$ ), coincident with the arrival of NB2 air mass at ground level. In the previous paragraph, we supposed a diabatic cooling of NB2 near the ground, induced by the high surface temperature and evaporation of hydrometeors, with a consequent density increment. In good agreement with this hypothesis, station A registers a density variation of $+13 \mathrm{~g} \mathrm{~m}^{-3}$. On the other hand, the pressure field remains almost unaltered. At $t=49 \mathrm{~min}$, with the arrival of NB1 air mass at surface level, a further change in temperature (decreasing by about $0.8^{\circ} \mathrm{C}$ in $4 \mathrm{~min}$, down to $25.5^{\circ} \mathrm{C}$ ) and density (increasing by about $7 \mathrm{~g} \mathrm{~km}^{-2}$ in $1 \mathrm{~min}$, up to $1.150 \mathrm{~kg} \mathrm{~m}^{-2}$ ) occurs. This perturbation is strong and rapid enough to produce a clear disturbance of the surface pressure field. Several pressure peaks are registered at station A, from $t=46$ and $t=52 \mathrm{~min}$. The pressure disturbance, with a maximum amplitude up to $32 \mathrm{~Pa}$, is measured just after the density peak occurrence. As observed in the vertical cross section of relative humidity, the downdraft transports large amounts of dry air from higher atmospheric layers. Accordingly, station A measures a RH drop by more than $40 \%$ after the arrival of NB1. The density peak is accompanied by a sensible rise of the horizontal surface wind speed, $U$, which increases by $10 \mathrm{~m} \mathrm{~s}^{-1}$ in $1 \mathrm{~min}$, from 5 to $15 \mathrm{~m} \mathrm{~s}^{-1}$. This value is very close to that expected for a surface outflow generated by a density current. According to theory, the horizontal wind velocity $\left(U_{\mathrm{e}}\right)$ produced by the action of cold pool weight is proportional to the height of denser layer $(h)$ and the difference between its density $\left(\rho_{\mathrm{dc}}\right)$ and that of environment $\left(\rho_{0}\right)$,

$U_{\mathrm{e}}=\sqrt{2 \frac{\rho_{\mathrm{dc}}-\rho_{0}}{\rho_{0}} g h}$.

Considering $\quad h=600 \mathrm{~m}, \quad \rho_{\mathrm{dc}}=1.15 \mathrm{~kg} \mathrm{~m}^{-3} \quad$ and $\rho_{0}=1.13 \mathrm{~kg} \mathrm{~m}^{-3}, U_{\mathrm{e}}$ is equal to $14.43 \mathrm{~m} \mathrm{~s}^{-1}$. Figure 4 shows the occurrence of negative temperature peaks with increasing time integration, corresponding to all the stations from 5 to $30 \mathrm{~km}$ away from downdraft center. The amplitude of such temperature changes decreases with increasing distance. After the arrival of the warmer and positively buoyant PB1 air mass $(t=52 \mathrm{~min})$, temperature undergoes a large increase (even becoming positive) and density perturbation is rapidly smoothed. Density maxima are also measured at stations $\mathrm{B}, \mathrm{C}, \mathrm{D}, \mathrm{E}, \mathrm{F}$ and $\mathrm{G}$, at $t=56.5,65.5,75.5$, 85.5, 97 and $112 \mathrm{~min}$, respectively. Assuming that density peaks identify the instantaneous position of the gust front's leading edge, we can estimate the average cold pool surface propagation velocity (in the rightward direction), equal to 33.6 (from $B$ to C), 30 (from C to D), 30 (from D to E), 26.4 (from $\mathrm{E}$ to $\mathrm{F}$ ) and 19.2 (from $\mathrm{F}$ to $\mathrm{G}$ ) $\mathrm{kmh}^{-1}$. The strongest density and pressure variations are observed at station $\mathrm{C}$, $10 \mathrm{~km}$ away from downdraft central point, with a pressure variation peak of $60 \mathrm{~Pa}$, in the real signal, and equal to $42 \mathrm{~Pa}$ in the high-pass-filtered signal of Fig. 4 . Beyond $10 \mathrm{~km}$, both maximum amplitude and propagation velocity of density and pressure disturbances decrease. Pressure change (somewhat proportional to the density variation) is reduced by more than 10 times as the gust front moves from station $\mathrm{C}$ to G. Similar considerations are valid for relative humidity and horizontal wind. The effects of cold pool propagation decrease accordingly, inversely proportional to its traveled distance. Farther than $20 \mathrm{~km}$ away from storm center, the decrease in $\mathrm{RH}$ is rather modest. The peaks in $U$ decrease down to 6-7 $\mathrm{ms}^{-1}$, remaining, however, quite evident (as the background wind field is almost zero) and consistent with the average density current propagation speed.

The nonhydrostatic effect generated by the collision of two fluids of different density can generate a pressure increase that is very close to that observed at the virtual station. To a first approximation, assuming a steady and incompressible fluid, the impact of a colder outflow on the pressure signal at the stagnant point of a stream line can be estimated using the Bernoulli equation, in the form

$P_{\mathrm{nh}}=\frac{1}{2} \rho_{\mathrm{dc}} U^{2}$,

where $P_{\mathrm{nh}}$ is the nonhydrostatic dynamic pressure. We can apply Eq. (7) to surface observations from Fig. 4 to calculate the dynamic pressure impinging at station B. At the instant of pressure peak occurrence, the cold pool's density in $\mathrm{B}$ is about $1.152 \mathrm{~g} \mathrm{~kg}^{-1}$, while the outflow speed difference before and after the cold pool's arrival (i.e., the effective impact velocity of the two flows) is $5 \mathrm{~m} \mathrm{~s}^{-1}$. On the other hand, the hydrostatic pressure can be estimated from the average density increase, due to the cold pool's propagation in the three lower atmospheric layers $(460 \mathrm{~m})$, which is about $0.01 \mathrm{~kg} \mathrm{~m}^{-3}$. The sum of the hydrostatic (45.13 Pa) and nonhydrostatic ( $14.4 \mathrm{~Pa})$ term is very close to the observed value of $60 \mathrm{~Pa}$ and the increase in dynamic pressure accounts for $24 \%$ of the total pressure variation.

\subsubsection{Sensitivity experiments}

Many previous studies stress that temperature lapse rate as well as moisture content are primary factors in regulating deep convection. As one would expect, Wu et al. (2009) find a systematic dependence of convection occurrence on atmospheric lapse rate and humidity profile. They show that the transition from shallow to deep convection happens earlier in more unstable and moister environments. In their experiment, however, convective inhibition of dry environments can be compensated by additional CAPE (convective available potential energy) from a lower initial potential temperature lapse rate. Numerous works confirm the importance of lapse rate in initiating deep convection. In particular, Houston and Niyogi (2007) suggest the presence of a critical lapse rate, even more unstable than required by the conditionally unstable condition, counteracting the rate of reducing buoyancy due to entrainment. 
$\mathrm{Wu}$ et al. (2009) show that convection is sensitive to very small variation of environmental lapse rate (less than $0.2 \mathrm{~K} \mathrm{~km}^{-1}$, below $10 \mathrm{~km}$ ). In this section, we analyze some of the effects of using different tropospheric lapse rates (i.e., below $15.5 \mathrm{~km})$ that vary with respect to the benchmark simulation by a few percentage units: $-1 \%\left(-0.035 \mathrm{~K} \mathrm{~km}^{-1}\right)$, $-0.5 \% \quad\left(-0.0175 \mathrm{~K} \mathrm{~km}^{-1}\right), \quad+0.5 \% \quad\left(-0.0175 \mathrm{~K} \mathrm{~km}^{-1}\right)$, $+1.0\left(+0.035 \mathrm{~K} \mathrm{~km}^{-1}\right),+1.5 \%\left(+0.0525 \mathrm{~K} \mathrm{~km}^{-1}\right),+2 \%$ $\left(-0.07 \mathrm{~K} \mathrm{~km}^{-1}\right)$ and $+5 \%\left(+0.175 \mathrm{~K} \mathrm{~km}^{-1}\right)$. All other initial parameters (e.g., the humidity profile) remain constant, while the lapse rate is varied. Results are summarized in Fig. 5, which shows the absolute variation ground wind speed, $U\left[\mathrm{~m} \mathrm{~s}^{-1} \mathrm{~min}^{-1}\right.$ ], within $1 \mathrm{~min}$ plotted as a function of the surface density increase $\left[\mathrm{kg} \mathrm{m}^{-3} \mathrm{~min}^{-1}\right]$, during the same time interval. $U$ and $\rho$ variations are calculated for each $10 \mathrm{~s}$ time step, $i$, as the absolute difference between the value at $t=(6 \times i)$ and that at $t=i$ (i.e., $1 \mathrm{~min}$ before), occurring within a radius of $45 \mathrm{~km}$ from the domain center and $t>40$ min (to neglect the moments prior to convective dynamics). In good agreement with expectations, surface outflow velocities seem proportional to rapid changes of surface air density. In all cases, stronger density perturbations are correlated with higher outflow velocities. The correlation is somewhat linear. The calculated linear regression is overplotted in the figure, where the data points have the same color as their corresponding experiments. For the entire data set (522 450 points), the fit slope is equal to 314.4 (black dashed line), with and a linear correlation coefficient $r=0.76$.

In the bottom image, we report the occurrence frequency (from 0 to 1 ) of density variations, for the eight different lapse rate increments. The histogram shows that small changes in reference lapse rate (from -1 to $+1.5 \%$ ) can induce surface density variations up to a maximum of $20 \mathrm{~g} \mathrm{~m}^{-3} \mathrm{~min}^{-1}$. However, the frequency of occurrence becomes particularly low for density increases larger than $10 \mathrm{~g} \mathrm{~m}^{-3}$. Beyond this value, only lapse rate variations equal to or stronger than $2 \%$ show a significantly larger occurrence. For $\Delta \Gamma$ equal to $2 \%$ and $5 \%$, the maximum value of surface density rate of variation increases up to more than $25-30 \mathrm{~g} \mathrm{~m}^{-3} \mathrm{~min}^{-1}$. A lapse rate of $3.57 \mathrm{~K} \mathrm{~km}^{-1}$ seems to be a threshold value beyond which strong and rapid surface density changes $\left(>10 \mathrm{~g} \mathrm{~m}^{-3} \mathrm{~min}^{-1}\right)$ are much more frequent than in more stable environments. In particular, a slight variation of the environmental lapse rate of about $0.02 \mathrm{~K} \mathrm{~km}^{-1}$, from $3.55(\Delta \Gamma=1.5 \%)$ to $3.57(\Delta \Gamma=2 \%)$, radially affects cloud development. But what drives this particular atmospheric response? This can be explained easily by looking closely at cloud evolution, in the case of $\Delta \Gamma \geq 2 \%$. Convective dynamics are enhanced, and the downdraft, which forms in the middle of the storm within the precipitation region, is particularly violent. The resulting surface density current gives rise to a very large updraft, at its boundary, that triggers new convection. This allows for continuous transport of moist air well above the level of free convection (warmed and lifted up until condensation) from the boundary layer

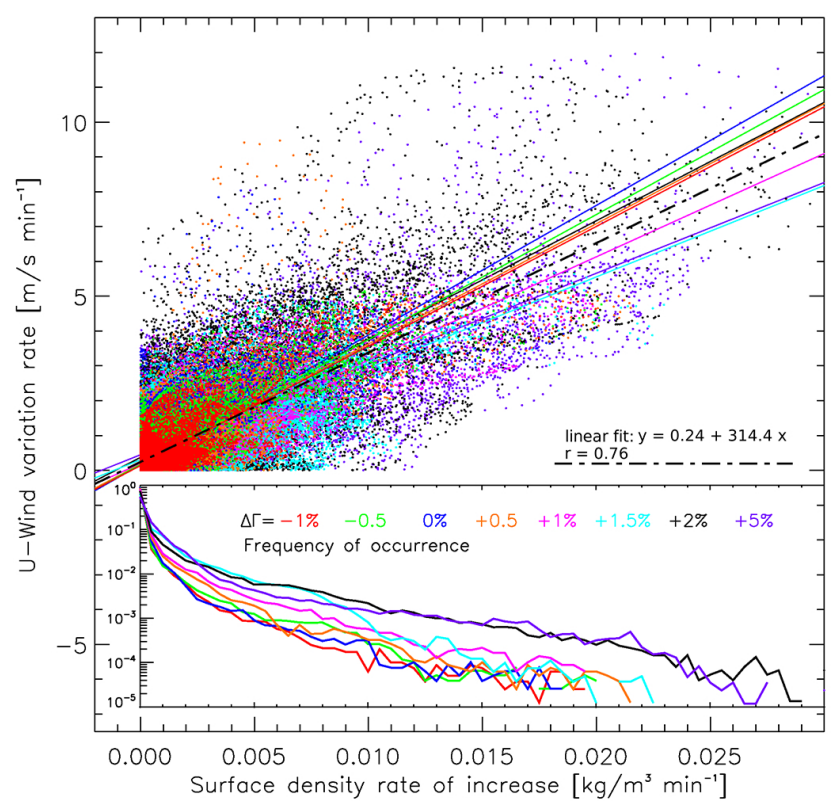

Fig. 5. Top image: absolute variation rate of $U$-wind component $\left[\mathrm{m} \mathrm{s}^{-1} \mathrm{~min}^{-1}\right]$, plotted as a function of surface density rate of increase $\left[\mathrm{kg} \mathrm{m}^{-3} \mathrm{~min}^{-1}\right]$, for the eight environmental potential temperature lapse rate increments $\Delta \Gamma$ (all other variables remaining constant), reported in the figure with the same colors for data points as their corresponding experiments. $U$ and $\rho$ variations are calculated for each $10 \mathrm{~s}$ time step, as the absolute difference between their value at a certain instant and that $1 \mathrm{~min}$ (i.e., six time steps) before, and occurring within a radius of $45 \mathrm{~km}$ from domain center and $t>40 \mathrm{~min}$. The calculated linear fit of the whole data set (522450 points) is reported, together with the estimate of linear regression coefficient, $r=0.76$. Inset bottom image: frequency of occurrence, from 0 to 1 , of surface density rate of increase. Horizontal scales of top and bottom image coincide.

to the cloud upper layer. The cloud anvil rapidly grows in size, reaching a horizontal extent of $100 \mathrm{~km}$. In the central part of the storm, the precipitation field remains particularly strong and the largely negative buoyancy in turn promotes new and stronger downdrafts. A multicell convective system (connected by a common cloud anvil) forms, even in the absence of wind shear. Larger surface density variations than in the case of single-cell cloud may occur. Main phases of this MCS formation mechanism are reported in Fig. 6, showing how the mechanical lifting effect enhances the vertical moisture transport. The vertical cross section of buoyancy, in the case of $\Delta \Gamma=5 \%$, is shown for $t=50,60$ and $180 \mathrm{~min}$. At $t=50 \mathrm{~min}$ (while the single-cell convective system is close to termination of its life cycle), dynamics instabilities are strong enough to lift up positively buoyant air (up $+0.2 \mathrm{~m} \mathrm{~s}^{-2}$, between 2 and $4 \mathrm{~km}$ at both cloud sides) to a sufficient altitude to allow for free convective transport. Ten minutes later, the same air masses have moved up to 6 and $12 \mathrm{~km}$ altitude, providing further water supply to the cloud's upper layers. At $t=180 \mathrm{~min}$, the cloud anvil extends more 

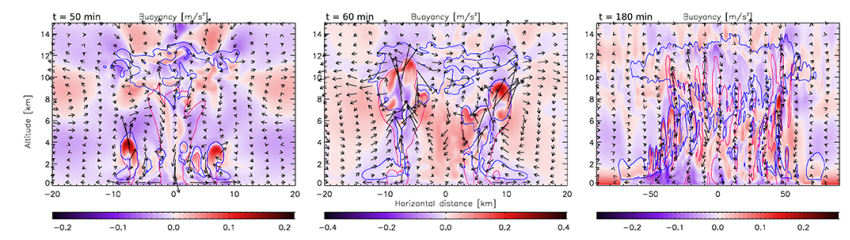

Fig. 6. Idealized simulation. Vertical cross section of buoyancy $\left[\mathrm{ms}^{-2}\right]$, at $t=50,60$ and $180 \mathrm{~min}$ (from left to right). The environmental potential temperature lapse rate is increased by $\Delta \Gamma=5 \%$ with respect to the benchmark simulation, while all other initial parameters are unchanged.

than $100 \mathrm{~km}$. As the humidity profile remains unchanged with respect to the benchmark simulation, the vertical transport of moisture by the forced updraft seems to be very important, insofar as the updraft becomes the primary factor regulating the amount of moisture available to future convection in the MCS.

The filtered signal of surface pressure variation shows the occurrence of a peak value equal to $60 \mathrm{~Pa}$ (about $30 \%$ larger than that obtained in the benchmark simulation, using the same cutoff frequency), after $80 \mathrm{~min}$ of time integration, at a distance of $15 \mathrm{~km}$ from domain center. In addition, the multicell structure of the cloud system allows for the development of multiple downdrafts with secondary pressure peaks, registered over the same station about $20 \mathrm{~min}$ after the occurrence of the first and strongest pressure disturbance.

\subsection{Station IS17}

Figure 1 (top image) shows the advection of a stratocumulus cloud field over the station, transported from east to west by trade winds (as indicated by the red arrow), for the day of interest. In the following paragraphs, temporal expressions are expressed in UTC (Universal Time Coordinated). The MCS passes over the Ivory Coast, starting from 13:00 (not shown) and over station IS17 at approximately 17:00. The surface pressure time record captured by sensor number 1 of station IS17 is presented in Fig. 1 (bottom image). The retrieved signal, treated with a low-pass filter of $25 \mathrm{~s}$, shows a clear pressure peak up to $12 \mathrm{~Pa}$ at about 15:30. Note that the raw signal has been jet-filtered by the sensor with an intensity attenuation of $20 \mathrm{~dB}$ per decade for frequencies below $0.01 \mathrm{~Hz}$. This means, for instance, that the corrected pressure response for a wave with period of $30 \mathrm{~min}$ and maximum amplitude of $28 \mathrm{~Pa}$ is equal to $2 \mathrm{~Pa}$. Thus, the $12 \mathrm{~Pa}$ pressure variation peak captured by IS17 indicates that a strong pressure increase occurred in a very small time window of about $10 \mathrm{~min}$. In the following minutes, the pressure signal is affected by several minor disturbances until 17:00. Subsequent to this, the measured perturbation is close to zero. The satellite image of the Ivory Coast at 15:30 is not available. However, at both 15:00 and 16:00, the cloud system is located south and east of station IS17, but not above it.
The arrival times of the first and stronger peak registered by the four microbarometers show that a pressure disturbance is registered first by sensor 2 and then by 3,1 and 4. Simple geometrical considerations lead to the conclusion that the arrival of the disturbance wave is between E and ENE (Fig. 2), consistent with the position of the approaching mesoscale cloud system. It is thus reasonable to believe that the pressure anomalies may be due to some kind of dynamic or thermodynamic perturbation (e.g., density current, gravity wave) generated within the MCS that subsequently propagated up to IS17. To further test such a hypothesis, we look at temperature, pressure, wind speed and direction estimates provided by the meteorological station, represented in Fig. 7 by a dotted line. To eliminate high-frequency oscillations, wind measurements (collected with a sampling time of $1 \mathrm{~s}$ ) are averaged over a period of $30 \mathrm{~s}$. The meteorological station is equipped with a barometer, which is not able to detect rapid surface pressure disturbances with the same sensitivity and resolution of the infrasound station. The resulting signal appears dominated by long-period variations that oscillate between values of 990 and $995 \mathrm{hPa}$. A slow but sensible surface pressure depression of about $5 \mathrm{hPa}$ occurs from 12:00 to 15:30. Even if the pressure peak is not fully resolved, we can observe a small hump in the surface pressure signal at 15:30 (shown in Fig. 7 as an orange vertical line), just before a much stronger increase with a larger period. This pressure enhancement is preceded, within a few minutes, by a strong variation of temperature, wind speed and direction. As observed in the idealized case, the near-simultaneous change of these three variables is the typical signature of a density current, when a colder and denser layer moves radially outward from its generating downdraft. Surface temperature, which drops down during the night of 2 April (from 27 to $24^{\circ} \mathrm{C}$ ), begins to sensibly increase starting from 06:30, until reaching its maximum value of $36^{\circ} \mathrm{C}$ at $15: 00$. Following this, it undergoes a rapid and dramatic drop by about $14^{\circ} \mathrm{C}$, from 36 to $22^{\circ} \mathrm{C}$, in about $30 \mathrm{~min}$. Before $15: 00$, wind speed is relatively low and does not generally exceed $4-6 \mathrm{~m} \mathrm{~s}^{-1}$. Its direction is fairly homogeneous, varying between 180 and $270^{\circ}$, in good agreement with the mean low-level circulation over West Africa in that period. Immediately after the temperature drop, the wind field suddenly turns $180^{\circ}$ (from W to E) in less than $30 \mathrm{~min}$ (consistent with the $\mathrm{E}$ or ENE direction of the disturbance wave, captured by IS17 infrasound sensors at 15:30 and shown in Fig. 2). Surface wind intensity increases almost instantaneously by $13 \mathrm{~m} \mathrm{~s}^{-1}$, up to $15 \mathrm{~m} \mathrm{~s}^{-1}$, which is in good agreement with the value expected in the case of cold pool propagation. From 17:00, the surface wind direction is SW again and its speed decreases to $1-3 \mathrm{~m} \mathrm{~s}^{-1}$, suggesting the end of the perturbation's effect. 

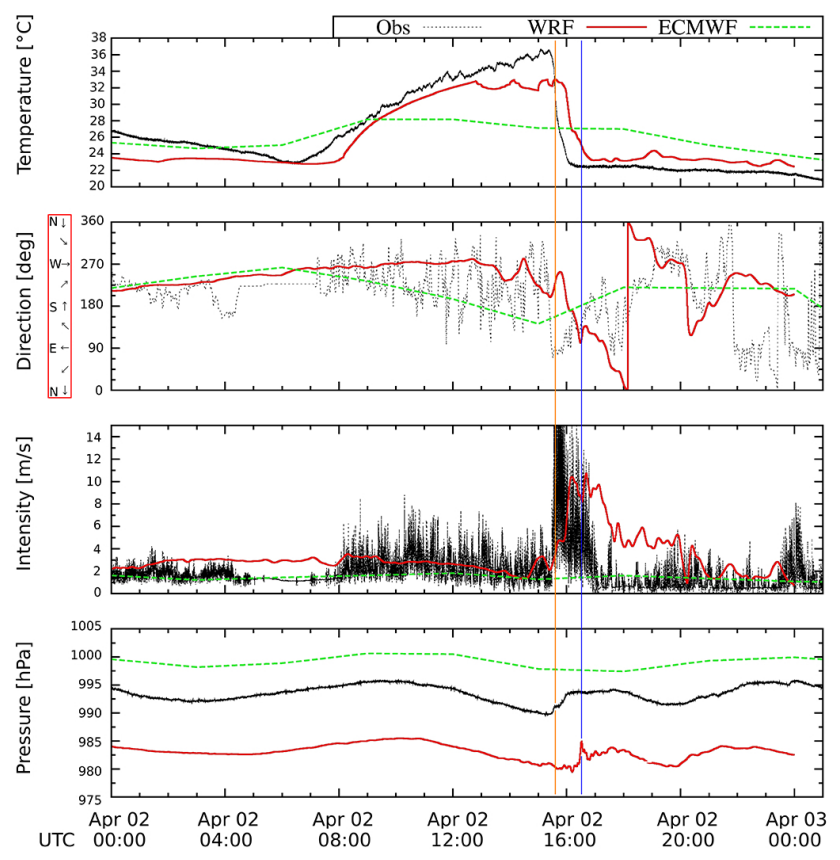

Fig. 7. Real simulation (red line), in situ observation of meteorological station IS17 (black dots) and ECMWF reanalysis data (dashed green line). Surface time records of temperature $\left[{ }^{\circ} \mathrm{C}\right]$, wind direction [degrees], wind intensity $\left[\mathrm{m} \mathrm{s}^{-1}\right]$ and total pressure $[\mathrm{hPa}]$, plotted as a function of time (UTC), on 2 April 2012.

\subsection{Real simulation}

\subsubsection{Time record}

Real simulation allows us to simulate the events that induced the occurrence of the pressure peak, temperature drop and wind intensity enhancement in the E direction, as observed by the microbarometer and meteorological station IS17. Figure 9 shows a horizontal cross section of the surface temperature at 17:00 for 2 April 2012. The position of station IS17, situated east of Lake Kossou, is marked as a red square. Color shading represents the surface temperature, with overplotted horizontal wind vectors (the scale of the arrows is shown in the figure) and contour lines of convective and nonconvective surface precipitation. Over the northern part of the Ivory Coast, the temperature $T$ can be particularly high and reach up to $40^{\circ} \mathrm{C}$. A large region between IS17 and the Atlantic Ocean, with a diameter of approximately $300 \mathrm{~km}$, is characterized by a temperature field that ranges between 20 and $28^{\circ} \mathrm{C}$. Rain develops initially on the east side and drifts westward under the effect of trade winds. At 17:00, the precipitation field extends to a higher altitude than ground level (not shown), which extends over almost half of the colder region, west of $4.5^{\circ} \mathrm{W}$, while surface precipitation (red contours) is located principally on the leeward side.

Note that ECMWF data used to nudge the numerical simulation have a coarser spatial $\left(1^{\circ}\right)$ and temporal $(3 \mathrm{~h})$ res- olution than the model. For this reason, and because initial conditions are lacking at the model resolution, it is impossible to perfectly simulate the fields associated with actual meteorological events. In our observed event, satellite images show that at 17:00, the real cloud system extends not only south but also east of IS17 and covers a wider area than that affected by the simulated temperature drop below $28^{\circ} \mathrm{C}$. However, the size of the simulated MCS is large enough to give rise to a large convective precipitation system that relatively well reproduces the thermodynamic disturbances recorded at IS17. Observations of simulated surface temperature, pressure, wind speed and velocity fields are reported in Fig. 7 (solid red line), together with in situ measurements of IS17 and ECMWF data (dashed green line). As IS17 is rather far from the simulated thunderstorm core, output variables are measured at a different point, which is closer to convective rain events. This virtual station (referred to hereafter as VS17) is situated about $135 \mathrm{~km}$ away from IS17 and its position $\left(5.80^{\circ} \mathrm{N}, 5.70^{\circ} \mathrm{W}\right)$ and is indicated by a yellow square in Fig. 7. ECMWF data are sparse but in relatively good agreement with both IS17 and WRF, before 15:30 and after 18:00 (i.e., before and after the strongest temperature perturbation). These data represent a temporally and spatially averaged state of the atmosphere. Their comparison with instantaneous ground measurements can be considered only a qualitative indicator to check the overall coherence of IS17 and VS17 retrievals.

One of the most interesting features is that WRF well reproduces a temperature drop that induces dynamic and thermodynamic disturbances, very similar to that observed at IS17 and consistent with a density current propagation. During the night and early morning, simulated surface temperatures are almost constant and equal to approximately $23^{\circ} \mathrm{C}$. Surface temperature starts to increase at 08:00 and reaches its maximum of $33^{\circ} \mathrm{C}$ at $15: 30$. With respect to in situ observations, simulated temperatures are underestimated by up to $4{ }^{\circ} \mathrm{C}$. The largest errors occur at midnight (00:00) corresponding to the warm peak (15:30). The temperature drop begins at 16:00 and terminates at 17:00. Then, $T$ remains almost constant and equal to $23^{\circ} \mathrm{C}$ during the following hours. In the afternoon, WRF seems to overestimate the temperature field by $1^{\circ}$. Besides being shifted by about $30 \mathrm{~min}$, the magnitude of simulated $T$ drop $\left(10^{\circ}\right)$ is smaller and less rapid $(1 \mathrm{~h})$ than that observed at IS17. However, it is sufficiently strong and violent to perturb the surface pressure field in the same way the real temperature drop does. Time records of temperature perturbations (i.e., the difference between $T$ and the environmental mean value), density, horizontal wind and pressure variations, acquired at VS17 at $100 \mathrm{~m}$ altitude, are represented in Fig. 8. This specific retrieval altitude allows for direct comparison with idealized case simulation data relative to the lower atmospheric layer between 0 and $150 \mathrm{~m}$.

During the night, morning and early afternoon, the temperature perturbation at the virtual station is about $5-6^{\circ} \mathrm{C}$. Starting from 16:00 and continuing until 17:00, the temperature 
VS17 station, 02 April 2012
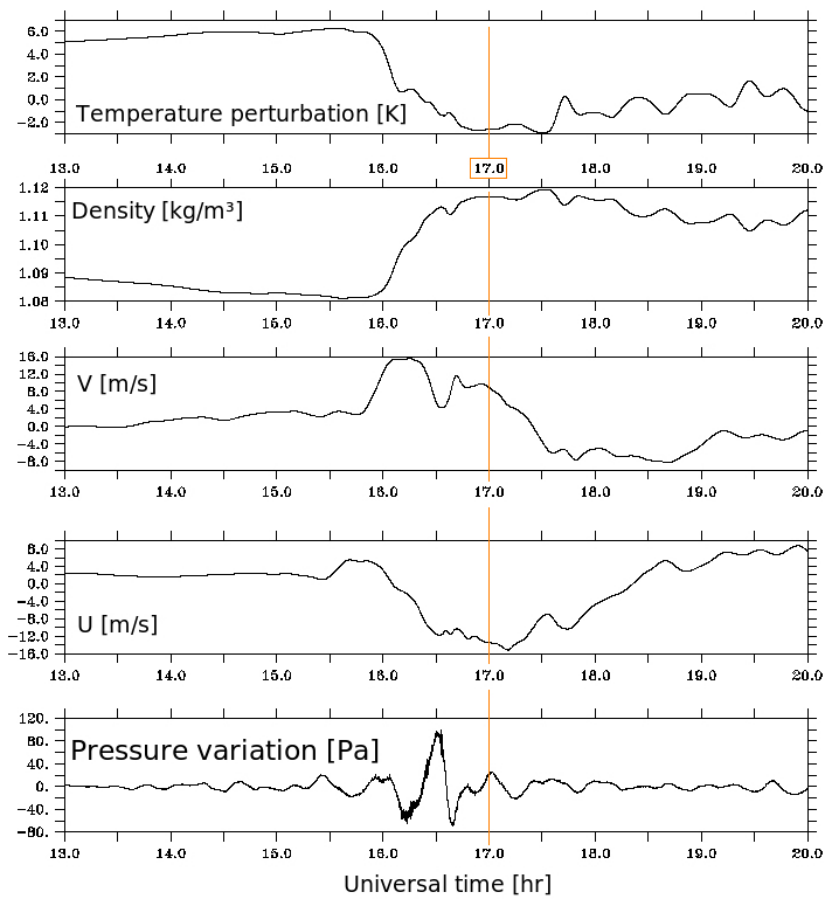

Fig. 8. Real simulation. Time records of temperature perturbation [K], density $\left[\mathrm{kg} \mathrm{m}^{-3}\right]$, horizontal $V$ - and $U$-wind velocity $\left[\mathrm{m} \mathrm{s}^{-1}\right]$, and pressure variation $[\mathrm{Pa}]$ retrieved at $100 \mathrm{~m}$ altitude above the virtual station VS17, on 2 April 2012. Variable perturbation and variation are defined as in Fig. 3 and Fig. 4, respectively.

decrease is so significant that local air masses become colder than the environmental average, by about $2{ }^{\circ} \mathrm{C}$. In the same time period, the weight of colder air parcels grows dramatically and the density of air masses increases by $3.6 \%$, from 1.08 to $1.12 \mathrm{~kg} \mathrm{~m}^{-3}$. The thermodynamic response of the local atmosphere to such temperature and density change occurs $30 \mathrm{~min}$ after the beginning of the perturbation. The pressure readjustment is violent and attains a maximum amplitude of $3 \mathrm{hPa}$ near 16:30. The pressure variation (with respect to a hydrostatically stable reference state) measured at VS17 and reported in Fig. 8 is treated with a high-pass filter of $2500 \mathrm{~s}$ to eliminate pressure oscillations associated with spatial scales of hundreds of kilometers. The strongest pressure disturbance occurs about $1 \mathrm{~h}$ later than the first peak pressure registered by the IS17 infrasound sensor and is much stronger, with a maximum amplitude of about $100 \mathrm{~Pa}$. This is also larger than the peak value obtained in the idealized simulation, 42 and $60 \mathrm{~Pa}$, in 2-D single-cell and multicell convective systems, respectively. This can be explained by the larger area occupied by this multicell rainstorm with respect to idealized simulation, but may also suggest a possible underestimation of convention effects in the 2-D model. Note that WRF simulates only a single peak, while the secondary pressure perturbations shown in the filtered signal of IS17 microbarometer, from 15:40 to $16: 40$, are not reproduced. This can be likely due to the presence of (1) other deep convective events that occur in a different region and after that simulated by WRF and (2) storm-induced gravity waves that may modulate and contribute to short-period surface pressure variations in a way that needs to be better understood and quantified in further studies. Besides the time shift of $1 \mathrm{~h}$, the last main discrepancy between IS17 and VS17 retrieved total surface pressure is a constant bias of about $5 \mathrm{hPa}$. This can be reasonably explained by the different altitude of the two stations (an altitude variation of $10 \mathrm{~m}$ corresponds to a change of $1 \mathrm{hPa}$ in surface pressure).

The overall agreement between IS17 and VS17 observations is confirmed from surface wind comparisons. While WRF overestimates the intensity of wind speed by $1 \mathrm{~ms}^{-1}$ before 08:00, the agreement is very good from 08:00 to $15: 30$, as is the case for the mean wind direction. The temperature drop occurs at 16:00 and is preceded slightly by a drastic variation of both wind velocity and direction. Speed intensity increases almost instantaneously by $6 \mathrm{~m} \mathrm{~s}^{-1}$, from 5 to $11 \mathrm{~m} \mathrm{~s}^{-1}$, and its direction changes from $\mathrm{W}$ to $\mathrm{E}$ in slightly more than $30 \mathrm{~min}$. As for surface temperature and pressure, the simulated field perturbation is smaller in magnitude and occurs less rapidly than registered by in situ observations. After 17:00 wind direction keeps turning counterclockwise, reaching a pure southward direction at 18:00. From 19:30, a SW mean flow is reestablished (consistent with the seasonal West African low-level circulation). The time window between 17:00 and 19:00, which immediately follows the strongest thermodynamic perturbations, is when simulated wind and in situ measurements show the largest discrepancy. Simulated wind field overestimates real intensity by about $4 \mathrm{~m} \mathrm{~s}^{-1}$ and the direction by up to $180^{\circ}$.

\subsubsection{Cold pool}

The presence of a descending colder and moister air column within the boundary layer is shown in Fig. 9. The position where the downdraft hits the ground and spreads out can be detected easily looking at the wind vectors. Within the colder region (light- and dark-blue region), arrows diverge radially and point outward over a relative wide area. The occurrence of a well-developed and extended cold pool over VS17 is shown definitively by Fig. 10. It represents a vertical slice (from 0 to $6 \mathrm{~km}$ altitude) of the atmospheric equivalent potential temperature perturbation (with respect to the domain average, at given altitude) at 17:00 (i.e., just after the temperature drop), along a meridional line overpassing the station.

The horizontal axes represents the S-N distance in kilometers from the southern border of the smallest grid. The position of station VS17 (at $426 \mathrm{~km}$ ) is indicated by a red square. The presence of a sensibly denser layer below $2500 \mathrm{~m}$ is stressed by solid (positive values) and dashed (negative values) red contour lines, which represent the local density perturbation in $\mathrm{g} \mathrm{m}^{-3}$. As in the idealized case, air masses 


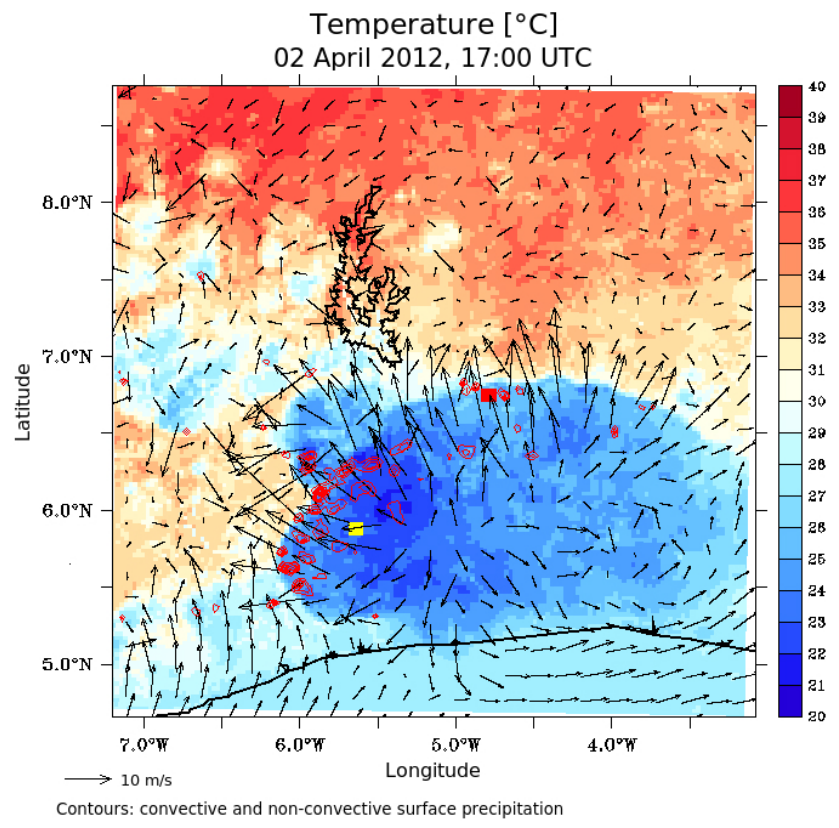

Fig. 9. Real simulation. Horizontal cross section of surface temperature field on 2 April 2012 at 17:00 UTC. The positions of IS17 $\left(6.670^{\circ} \mathrm{N}, 4.850^{\circ} \mathrm{W}\right)$ and $\operatorname{VS} 17\left(5.80^{\circ} \mathrm{N}, 5.70^{\circ} \mathrm{W}\right)$ are indicated by a red and a yellow square symbol, respectively. Contours of convective plus nonconvective surface rain water mixing ratio are overplotted, as are wind vectors. The length of an arrow is proportional to wind intensity, as indicated in the figure's legend.

with density up to $1-3 \mathrm{~g} \mathrm{~m}^{-3}$ higher than the environment are advected outward, up to several kilometers away from downdraft center, by the surface wind. Under the force exerted by the weight of denser layer, wind field attains its maximum intensity corresponding to the stronger density anomalies. Meridional and longitudinal (perpendicular to the plane of Fig. 10) components of the horizontal wind field, measured at $100 \mathrm{~m}$ altitude over the station VS17, are shown in Fig. 8. At 17:00, just after the temperature drop and local density enhancement, $V$ is directed northward $\left(8 \mathrm{~m} \mathrm{~s}^{-1}\right)$ and $U$ reaches its daily maximum value in the westward direction $\left(-16 \mathrm{~m} \mathrm{~s}^{-1}\right)$ for an absolute magnitude of $18 \mathrm{~m} \mathrm{~s}^{-1}$ in the WNW direction.

The dark-blue coloring within the solid contours in Fig. 10 indicates a negative value of equivalent potential temperature anomaly. It reaches $-5 \mathrm{~K}$ in the denser region, indicating an extremely stable subcloud layer. The colder air at VS17 is transported into the PBL from above, where the colder layer is deeper and wind vectors are directed downwards. The resulting cold pool can be identified as the whole region with density and equivalent potential temperature respectively higher (from 1 to $3 \%$ ) and lower than surrounding air. This cold pool extends northward for approximately a hundred kilometers, with a vertical depth of $1500 \mathrm{~m}$. Both vertical and horizontal extensions are 4 times larger than those obtained in the idealized simulation, where a $500 \mathrm{~m}$

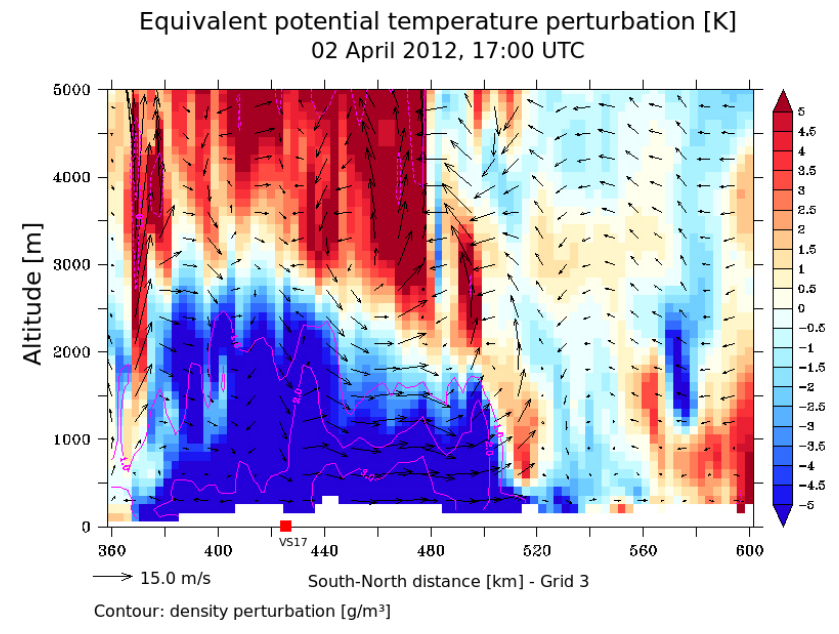

Fig. 10. Real simulation. Vertical cross section, between 0 and $5 \mathrm{~km}$ altitude, of equivalent potential temperature perturbation $[\mathrm{K}]$ on 2 April 2012 at 17:00 (UTC), calculated over a south-north plane coincident with the position of station VS17 (indicated by a red square symbol). Perturbation is defined as in Fig. 3. The $x$ axes represent the distance from the southern bound of the inner model grid. White spaces at ground level indicate surface elevation. Wind vectors and contours (with solid and dotted line for positive and negative values, respectively) of percentage density perturbation (i.e., with regard to domain average) are overplotted. The length of an arrow is proportional to wind intensity, as specified in the figure's legend.

width density current extends up 30 kilometers away from the downdraft center.

The idealized case has shown that, moving outward, colder air is pushed under the warmer cloud inflow, which is lifted up at the pool's boundaries. Because of its high humidity and temperature, an air mass with a high equivalent potential temperature becomes rapidly buoyant, creating updrafts. The resulting instabilities at the density current's leading edge are shown in Fig. 10, at horizontal coordinates of 360-380 and $500-520 \mathrm{~km}$, where cold pool is up to $1 \%$ denser than surrounding air. The more stable layer replaces the subcloud layer, with an equivalent potential temperature anomaly up to $4-5 \mathrm{~K}$. The associated vertical updraft reaches up to $3 \mathrm{~km}$ altitude.

Results seems to suggest that density current propagation is likely the leading factor in triggering new convection at the MCS boundary, explaining why convective rain is mostly located along the convective line.

\section{Summary and conclusion}

In this work we performed idealized and real WRF simulations in order to study the development of single- and multiple-cell convective storms in tropical regions and the way they interact with surface and thermodynamic fields. 
Results are then compared with in situ measurements, provided in the framework of ARISE project, by an infrasound station of the IMS network.

The idealized 2-D model configuration allows for an indepth analysis of a single-cell deep convective cloud generation in a very simplified and controlled environment. The initial atmosphere is at rest and convection is kicked off by a temperature instability (warm bubble) of $2 \mathrm{~K}$. The cloud forms after $7.5 \mathrm{~min}$ of time integration and grows rapidly in size, surpassing $12 \mathrm{~km}$ altitude after $35 \mathrm{~min}$. Precipitation quickly develops after $14 \mathrm{~min}$. Cloud dynamics are driven by a deep convective circulation extending from the boundary layer to the upper troposphere. The strongest upward velocities (up to $30 \mathrm{~m} \mathrm{~s}^{-1}$ ) are observed in the middle of the cloud, within the strong positively buoyant updraft, generated by the initial warm bubble. At both cloud sides, negatively buoyant air subsides from cloud top, at about $10 \mathrm{~m} \mathrm{~s}^{-1}$. With increasing time integration, buoyancy is reduced by entrainment of dry and negatively buoyant air from outside the cloud, as well as by water loading of precipitation from within the cloud. The combined effect of these two mechanisms enhances downdraft strength, leading to a descending air column that reaches the ground after $40 \mathrm{~min}$ of time integration. Falling down from an altitude up to $7.5 \mathrm{~km}$, and with a maximum speed of $17 \mathrm{~m} \mathrm{~s}^{-1}$, the downdraft undergoes an adiabatic increase in temperature and density, enhanced by the low moisture content (20-40\% lower than surrounding air). The peak of negative buoyancy reaches the PBL after $47 \mathrm{~min}$. In the very last few hundred meters, it is subjected to a violent diabatic cooling, which induces a sudden temperature drop and a near-instantaneous density decrease. Two minutes later, the colder and denser layer spreads out at ground level, generating a density current about $500 \mathrm{~m}$ deep. The atmospheric response to this strong and rapid temperature change and density readjustment is a pressure perturbation, at cold pool leading edges, up to $60 \mathrm{~Pa}$. The peak of these thermodynamic anomalies moves radially outward, to a distance of $30 \mathrm{~km}$ away from domain center, where the pressure anomaly becomes 10 times smaller. The propagation velocity decreases with increasing distance traveled, from about 34 to $20 \mathrm{~km} \mathrm{~h}^{-1}$. The denser, colder, dryer and, hence, more stable layer replaces the former PBL air, which is lifted up, becoming rapidly unstable and forming new updrafts. As expected, the arrival of the cold pool is accompanied by a strong and sudden rise of surface $U$-wind intensity, up to $15 \mathrm{~m} \mathrm{~s}^{-1}$. Sensitivity experiments show that the surface wind speed increase is somewhat proportional to the surface density perturbation, being stronger in the case of more unstable environments. In particular, we find that a lapse rate exceeding $3.57 \mathrm{~K} \mathrm{~km}^{-1}$ substantially increases the occurrence of rapid density change, being larger than $10 \mathrm{~g} \mathrm{~m}^{-3} \mathrm{~min}^{-1}$. In this case, updrafts at cold pool boundaries are strong enough to lift air parcels up to their level of free convection. Triggering of new convection by the spreading cold pool causes the cloud system to become larger, and allows for continuous updraft production. We thus observe the genesis of a multicell convective system, topped by a common anvil with a horizontal extension of $100 \mathrm{~km}$ and lifetime of several hours. In good agreement with Khairoutdinov and Randall (2006), these results stress the primary role of cold pools in maintaining and organizing convective dynamics. Density current occurrence seems to be a leading factor in the transition of single-cell convective clouds to multicell systems and the development of MCS.

The thermodynamics disturbances generated by cold pool propagation are shown to produce short-period surface pressure anomalies, up to $42 \mathrm{~Pa}$ in the high-pass filtered signal, traveling to distances very far from their source. The filtered signals obtained from these pressure variations are consistent with those measured by the infrasound sensor of station IS17 during a tropical storm on 2 April 2012. In this case, however, the maximum amplitude is larger and equal to $100 \mathrm{~Pa}$, as generated by a multicell convective system.

The realistic 3-D simulation, nudged toward ECMWF reanalysis data, shows that the WRF model is able to reproduce, with relatively good accuracy, the dynamical and thermodynamical disturbances induced by a real tropical storm that were registered over the Ivory Coast on 2 April 2012. In this case, the model domain is composed of three nested grids. While the smallest grid, centered over the Ivory Coast, has a horizontal resolution of $3 \mathrm{~km}$ and no CPS is necessary to resolve convection, the other two use the KF scheme. The simulated MCS position is consistent with that of the cloud system observed in satellite images. Temperature, pressure and horizontal wind observations, recorded at ground level by station IS17, are in good agreement with those simulated at virtual station VS17. Apart from a time shift between 30 and $50 \mathrm{~min}$, WRF well reproduces the surface temperature evolution during the whole day, its drastic drop at about 15:30 (16:00 in WRF), the consequent change in wind field (velocity and direction) and the near-simultaneous pressure peak occurrence resolved by the microbarometer. Horizontal and vertical cross sections of temperature and equivalent potential temperature (respectively) show the presence of a large density current with a vertical depth up to $1.5 \mathrm{~km}$. Similarly to idealized case, we observe the substitution of the PBL air by a more stable layer, with the development of strong updraft at the edge of the cold pool.

The overall consistence and similarity between real and idealized model simulations demonstrates the capability of a simplified 2-D model to correctly represent convective dynamics and catch the main phase of single- or multicell convective cloud evolution. The surface pressure perturbation, measured by the IS17 microbarometer in proximity to a tropical storm, is accurately reproduced in both idealized and real experiments. The good agreement with in situ observation confirms the reliability of simulated results, identifying density current propagation as the leading factor in producing high-frequency pressure peak occurrence. This evidence, however, does not exclude a more or less direct involvement 
of gravity waves generated by the storm itself through a mass redistribution. Although the GW contribution in modulating the ground pressure field can be reliably inferred, the quantification of their effect exceeds the scope of this study and will be the object of further research.

The results presented in this paper show a strong and intimate link between rainstorm activity and surface pressure disturbances of relatively short period that propagate radially from their source. The combined information of at least two different stations (each of which equipped with four microbarometers and able to provide the propagating disturbance direction) would more precisely localize the position of convective downdraft and quantify the cold pool's propagation velocity (shown to be somewhat proportional to the induced density perturbation and hence to downdraft strength). The development of an infrasound station network, for constant monitoring of density current signature in surface pressure, would then allow for real-time tracking of MCS, which may open a wide range of future prospects for a continuous and highly resolved survey of storm activity.

Acknowledgements. The authors acknowledge the financial support by the European Union's Seventh Framework Programme, FP7.

Edited by: T. J. Dunkerton

\section{References}

Alcoverro, B. and Le Pichon, A.: Design and optimization of a noise reduction system for infrasonic measurements using elements with low acoustic impedance, J. Acoust. Soc. Am., 117, 17171727, doi:10.1121/1.1804966, 2005.

Betts, A. K.: The thermodynamic transformation of the tropical subcloud layer by precipitation and downdrafts, J. Atmos. Sci., 33, 1008-1020, doi:10.1175/15200469(1976)033<1008:TTTOTT>2.0.CO;2, 1976.

Beucher, F.: Méteorologie tropicale: des alizés au cyclone, Edité pat Météo-France, 865 pp., 2010.

Bolton, D.: The Computation of Equivalent Potential Temperature, Mon. Weather Rev., 108, 1046-1053, 1980.

Bony, S., Lau, K.-M., Sud, Y. C.: Sea surface temperature and large-scale circulation influences on tropical greenhouse effect and cloud radiative forcing, J. Climate, 10, 2055-2077, doi:10.1175/1520-0442(1997)010<2055:SSTALS>2.0.CO;2, 1997.

Brunk, I. W.: Squall lines, B. Am. Meteorol. Soc., 34, 1-9, 1953.

Byers, H. R. and Braham, R. R.: The Thunderstorm, US Weather Bureau, US Department of Commerce, Washington DC, 287 pp., 1949.

Costantino, L. and Bréon, F.-M.: Aerosol indirect effect on warm clouds over South-East Atlantic, from co-located MODIS and CALIPSO observations, Atmos. Chem. Phys., 13, 69-88, doi:10.5194/acp-13-69-2013, 2013.

Emanuel, K. A.: Atmospheric Convection, Oxford Univ. Press, New York, 580 pp., 1994.
Evers, L. G. and Haak, H. W.: Listening to sounds from an exploding meteor and oceanic waves, Geophys. Res. Lett., 28, 41-44, doi:10.1029/2000GL011859, 2001.

Fovell, R. G., Durran, D. R. and Holton, J. R.: Numerical simulations of convectively generated stratospheric gravity waves, J. Atmos. Sci, 49, 1427-1442, doi:10.1175/15200469(1992)049<1427:NSOCGS>2.0.CO;2, 1992.

Fujita, T. T.: Precipitation and cold air production in mesoscale thunderstorm systems, J. Meteorol., 16, 454-466, doi:10.1175/1520-0469(1959)016<0454:PACAPI>2.0.CO;2, 1959.

Fujita, T. T.: Analytical mesometeorology: a review, severe local storms, Meteor. Monogr., 27, 77-125, 1963.

Garcés, M., Caron, P., Hetzer, C., Le Pichon, A., Bass, H., Drob, D., and Bhattacharyya, J.: Deep infrasound radiated by the Sumatra earthquake and tsunami, Eos Trans. AGU, 86, 317-320, doi:10.1029/2005EO350002, 2005.

Heinrich, P. and Blanchard, X.: Simulation of atmospheric circulation over Tahiti and of local effects on the transport of $210 \mathrm{pb}$, Mon. Weather Rev., 137, 1863-1880, doi:10.1175/2008MWR2648.1, 2009.

Hetzer, C. H., Waxler, R., Gilbert, K. E., Talmadge, C. L., and Bass, H. E.: Infrasound from hurricanes: dependence on the ambient ocean surface wave field, Geophys. Res. Lett., 35, L14609, doi:10.1029/2008GL034614, 2008.

Hoskins, B. J. and Karoly, D. J.: The steady linear response of a spherical atmosphere to thermal and orographic forcing, J. Atmos. Sci., 38, 1179-1196, doi:10.1175/15200469(1981)038<1179:TSLROA>2.0.CO;2, 1981.

Houston, A. L. and Niyogi, D.: The sensitivity of convective initiation to the lapse rate of the active cloud-bearing layer, Mon. Weather Rev., 135, 3013-3032, doi:10.1175/MWR3449.1, 2007.

Kain, J. S. and Fritsch, J. M.: Convective parameterization for mesoscale models: the Kain-Fritsch scheme, the representation of cumulus convection in numerical models, edited by: Emanuel, K. A. and Raymond, D. J., Amer. Meteor. Soc., 246 pp., 1993.

Keenan, T., Rutledge, S., Carbone, R., Wilson, J., Takahashi, T., May, P., Tapper, N., Platt, M., Hacker, J., Sekelsky, S., Moncrieff, M., Saito, K., Holland, G., Crook, A., and Gage, K.: The Maritime Continent Thunderstorm Experiment (MCTEX): overview and some results, B. Am. Meteorol. Soc., 81, 2433-2455, doi:10.1175/1520-0477(2000)081<2433:TMCTEM>2.3.CO;2, 2000.

Kessler, E.: On the distribution and continuity of water substance in atmospheric circulation, Meteor. Monogr., 32, 84 pp., 1969.

Khairoutdinov, M. F. and Randall, D. A.: High simulation of shallow-to-deep convection transition over land, J. Atmos. Sci., 63, 3421-3436, doi:10.1175/JAS3810.1, 2006.

Kim, S.-Y. and Chun, H. Y.: Stratospheric gravity waves generated by typhoon saomai 2006: numerical modeling in a moving frame following the typhoon, J. Atmos. Sci., 67, 3617-3636, doi:10.1175/2010JAS3374.1, 2010.

Knievel, J. C. and Johnson, R. H.: Pressure transients within MCS mesohighs and wake lows, Mon. Weather Rev., 126, 1907-1930, doi:10.1175/1520-0493(1998)126<1907:PTWMMA>2.0.CO;2, 1998. 
Lane, T. P. and Moncrieff, M. W.: Stratospheric gravity waves generated by multiscale tropical convection, J. Atmos. Sci., 65, 2598-2614, doi:10.1175/2007JAS2601.1, 2008.

Lane, T. P. and Reeder, M. J.: Gravity wave breaking, secondary wave generation, and mixing above deep convection in a threedimensional cloud model, Geophys. Res. Lett., 33, L23813, doi:10.1029/2006GL027988, 2006.

Lane, T. P. and Reeder, M. J.: Convectively generated gravity waves and their effect on the cloud environment, J. Atmos. Sci., 58, 2427-2440, doi:10.1175/15200469(2001)058<2427:CGGWAT>2.0.CO;2, 2001.

Lane, T. P. and Clark, T. L.: Gravity waves generated by the dry convective boundary layer: two-dimensional scale selection and boundary-layer feedback, Q. J. Roy. Meteor. Soc., 128, 15431570, doi:10.1002/qj.200212858308, 2002.

Le Pichon, A., Guilbert, J., Vallé, M., Dessa, J. X., and Ulziibat M.: Infrasonic imaging of the Kunlun Mountains for the great 2001 China earthquake, Geophys. Res. Lett., 30, 1814, doi:10.1029/2003GL017581, 2003.

Lemone, M. A., Zipser, E. J., and Trier, S. B.: The role of environmental shear and thermodynamic conditions in determining the structure and evolution of mesoscale convective systems during TOGA COARE, J. Atmos. Sci., 55, 3493-3518, doi:10.1175/15200469(1998)055\%3C3493:TROESA\%3E2.0.CO;2, 1998.

Lenaerts, J. T. M., van Heerwaarden, C. C. and Vilà-Guerau de Arellano, J.: Shallow convection over land: a mesoscale modelling study based on idealized WRF experiments, Tethys, 6, 51-66, doi:10.3369/tethys.2009.6.04, 2009.

Ma, L.-M. and Tan, Z.-M.: Improving the behavior of the cumulus parameterization for tropical cyclone prediction: convection trigger, Atmos. Res., 92, 190-211, doi:10.1016/j.atmosres.2008.09.022, 2009.

Moeng, C.-H., McWilliams, J. C., Rotunno, R., Sullivan, P. P., and Weil, J.: Investigating $2 \mathrm{~d}$ modeling of atmospheric convection in the pbl, J. Atmos. Sci., 61, 889-903, doi:10.1175/15200469(2004)061<0889:IDMOAC>2.0.CO;2, 2004.

Moeng, C.-H., Dudhia, J., Klemp, J., and Sullivan, P.: Examining two-way grid nesting for large eddy simulation of the pbl using the wrf model, Mon. Weather Rev., 135, 2295-2311, doi:10.1175/MWR3406.1, 2007.

Molinari, J. and Dudek, M.: Parameterization of convective precipitation in mesoscale numerical models: a critical review, Mon. Weather Rev., 120, 326-344, doi:10.1175/15200493(1992)120<0326:POCPIM>2.0.CO;2, 1992.

Nesbitt, S. W., Cifelli, R., and Rutledge, S. A.: Storm morphology and rainfall characteristics of trmm precipitation features, Mon. Weather Rev., 134, 2702-2721, doi:10.1175/MWR3200.1, 2006.

Nicholls, M. E., Johnson, R. H., and Cotton, W. R.: The sensitivity of two-dimensional simulations of tropical squall lines to environmental profiles, J. Atmos. Sci., 45, 3625-3649, 1988.

Orlanski, I.: A rational subdivision of scales for atmospheric processes, B. Am. Meteorol. Soc., 56, 527-530, 1975.
Petch, J. C., Blossey, P. N., and Bretherton, C. S.: Differences in the lower troposphere in two- and three-dimensional cloud-resolving model simulations of deep convection, Q. J. Roy. Meteor. Soc., 134, 1941-1946, doi:10.1002/qj.315, 2008.

Sanders, F. and Emanuel, K. A.: The momentum budget and temporal evolution of a mesoscale convective system, J. Atmos. Sci., 34, 322-330, doi:10.1175/15200469(1977)034<0322:TMBATE>2.0.CO;2, 1977.

Sawyer, J. S.: Cooling by rain as the cause of the pressure rise in convective squalls, Q. J. Roy. Meteor. Soc., 72, 168, 1946.

Shige, S. and Satomura, T.: Western generation of eastward-moving tropical convective bands in toga coare, J. Atmos. Sci., 58, 3724-3740, doi:10.1175/15200469(2001)058<3724:WGOEMT>2.0.CO;2, 2001.

Skamarock, W. C., Klemp, J. B., Dudhia, J., Gill, D. O., Barker, D. M., Wang, W., and Powers, J. G.: A Description of the Advanced Research WRF Version 3, NCAR Technical Note TN-468+ST R. 113 pp., 2008.

Spiga, A., Teitelbaum, H., and Zeitlin, V.: Identification of the sources of inertia-gravity waves in the Andes Cordillera region, Ann. Geophys., 26, 2551-2568, doi:10.5194/angeo-262551-2008, 2008.

Tao, W.-K. and Simpson. J.: Modeling study of a tropical squall-type convective line, J. Atmos. Sci., 46, 177-202, doi:10.1175/1520-0469(1989)046<0177:MSOATS>2.0.CO;2, 1989.

Tompkins, A. M.: Organization of tropical convection in low vertical wind shears: the role of cold pools, J. Atmos. Sci., 58, 1650-1672, doi:10.1175/15200469(2001)058<1650:OOTCIL>2.0.CO;2, 2001.

Wakimoto, R. M.: The life cycle of thunderstorm gust fronts viewed with Doppler radar and rawinsonde data, Mon. Weather Rev., 110, 1060-1082, 1982.

Wang, H., Skamarock, W. C., and Feingold, G.: Evaluation of scalar advection schemes in the advanced research wrf model using large-eddy simulations of aerosol-cloud interactions, Mon. Weather Rev., 137, 2547-2558, doi:10.1175/2009MWR2820.1, 2009.

Wu, C.-M., Stevens, B., Arakawa, A.: What controls the transition from shallow to deep convection?, J. Atmos. Sci., 66, 17931806, doi:10.1175/2008JAS2945.1, 2009.

Yau, M. K. and Rogers, R. R.: Short Course in Cloud Physics, 3rd edn., published by Butterworth-Heinemann, 1 January 1989, 304 pp., 1989.

Yoneyama, K. and Parsons, D. B.: A proposed mechanism for the intrusion of dry air into the tropical western pacific region, J. Atmos. Sci., 56, 1524-1546, doi:10.1175/15200469(1999)056<1524:APMFTI>2.0.CO;2, 1999.

$\mathrm{Yu}, \mathrm{X}$. and Lee, T.-Y.: Role of convective parameterization in simulations of a convection band at grey-zone resolutions, Tellus A, 62, 617-632, doi:10.1111/j.1600-0870.2010.00470.x, 2010. 